\title{
Numerical analysis of propeller exciting force in oblique flow
}

\author{
Chao Wang ${ }^{1} \cdot$ Shengxia Sun $^{1} \cdot$ Shuai Sun ${ }^{1} \cdot \operatorname{Liang} \mathbf{L i}^{2}$
}

Received: 23 July 2016 / Accepted: 8 January 2017 / Published online: 13 May 2017

(C) The Author(s) 2017. This article is an open access publication

\begin{abstract}
CFD commercial software FLUENT, based on solving RANS equations, was used to calculate propeller hydrodynamic performance and exciting force. Sliding grid technique was applied to simulate the propeller rotation. Different advance coefficients and oblique inflow angles were set as different working conditions through adjusting inflow magnitude and direction. DTMB4679 propeller as the research object, hydrodynamic performance of this propeller in oblique flow was first calculated, and agreed well with test results. It verifies the accuracy of calculation method. The time-domain data of propeller exciting force under different working conditions was monitored, and then spectrum curve was obtained through fast Fourier transform. The results show that propeller load in oblique flow will aggravate, and transverse velocity component of oblique flow will cause great transverse force generated by propeller. Moreover, the smaller advance coefficient causes the greater peak of propeller fluctuating pressure. Additionally, oblique flow angle has a greater influence on unsteady bearing force than fluctuating pressure.
\end{abstract}

Keywords Propeller · Oblique flow $\cdot$ Hydrodynamic performance $\cdot$ Bearing force $\cdot$ Fluctuating pressure

\section{Abbreviations \\ D \\ $J$ \\ Diameter of propeller \\ Advance coefficient}

Chao Wang

wangchao806@hrbeu.edu.cn

1 College of Shipbuilding Engineering, Harbin Engineering University, Harbin 150001, China

2 China Ship Scientific Research Center, Wuxi 214082, China $\rho$

$P$

$\tau_{x x}$

$F_{x}$

$G_{\mathrm{k}}$

$G_{\omega}$

$Y_{k}$

$Y_{\omega}$

Y

$\mu$

$\tau_{m}$

$u_{j}$

$C_{P}=\frac{P-P_{0}}{1 / 2 \rho V_{R}^{2}}$

$\left(P-P_{0}\right)$

$V_{\mathrm{R}}=\sqrt{V_{\mathrm{x}}^{2}+(2 \pi n r)^{2}}$

$V_{\mathrm{x}}$

$V_{\mathrm{t}}$

$n$

$U$

$\omega$

$\beta$

$\theta$

$\alpha=\Theta-\arctan \left(\frac{V_{\mathrm{x}}}{V_{\mathrm{t}}}\right)$

$\Theta$

$K_{T i}=\frac{T_{i}}{\rho n^{2} D^{4}}$
Liquid density

Pressure of fluid element

Component of viscous stress

Mass force

Turbulence kinetic energy production item

Turbulence kinetic energy production item

Turbulence dissipative item

Turbulence dissipative item

Distance of unit center to wall

Kinetic viscosity

Wall shear stress

Instantaneous value of velocity in $j$

direction

Pressure coefficient

Relative pressure

Relative inflow velocity

Axial velocity component

Circumferential velocity

component

Speed of rotation

Oblique flow velocity

Propeller rotation angular velocity

Oblique flow angle

Circumferential position of blade

Angle of attack

Pitch angle

Propeller thrust coefficient 


$$
\begin{array}{ll}
K_{Q i}=\frac{Q_{i}}{\rho n^{2} D^{5}} & \text { Propeller torque coefficient } \\
K_{P}=\frac{P}{\rho n^{2} D^{2}} & \text { Fluctuating pressure coefficient }
\end{array}
$$

\section{Introduction}

There is periodical exciting force in the stern when propeller works in non-uniform flow field of three directions. The force will transfer to the hull through shaft system and flow, and obviously strengthens underwater noise and vibration on the hull. Propeller exciting force has been proposed internationally in the early 1960s, but people have worked on the research of propeller exciting force since 1970s. Sascha Merz et al. [1] applied finite element method to analyze the hull structure response and acoustic response under the action of propeller axial fluctuating force. The results indicate that the dynamic response of shaft system led by propeller exciting force will cause propeller vibration, and then the vibration causes that propeller generates additional sound radiation. Kornev [2] applied URANS-LES mixed method and made a detailed research of the stern wake flow of KVLCC2. The results show that the pulsation of propeller thrust in unsteady wake field is twice as the pulsation in timeaveraged wake field. It shows that the instability of wake field is very large. So it must be considered in calculating unsteady propeller load. Yingsan Wei et al. [3] used CFD to research unsteady hydrodynamic exciting force of five blades propeller behind model submarine, on this basis, and then they used finite element and boundary element model to calculate hull structure and acoustic response in frequency domain under the excitation of propeller exciting force. The calculation results show that propeller axial force makes most contribution to underwater noise of submarine. Additionally, the propeller transverse exciting force is larger than vertical exciting force. And the fluctuating force of single blade has large phase difference with the fluctuating force of whole propeller. Since twentyfirst century, Chinese scholars have also made plentiful and substantial achievements. Ye Jinming et al. [4] used theory and experience method to calculate the bearing force of conventional and unconventional propeller, and found that quasi-steady method can be widely used in the bearing force calculation of conventional propeller, while it is more reasonable for some unconventional propellers to use theoretical method including panel method and lifting surface method, such as highly skewed propeller. Tan Yanshou [5] used perturbation potential based on surface panel method to calculate unsteady propeller bearing force, and it had a good precision that calculating results are compared with test results. Chen Ruxing et al. [6] based on CFX sliding grid technique to predict unsteady hydrodynamic performance of propeller in axial wake field, and their calculating results agreed well with proposed value given by the literature. They also analyzed the varying pattern of propeller exciting force, and provided an analysis method for numerical calculation of propeller exciting force.

Oblique flow is a relatively simple non-uniform flow. Propeller working in the stern is often in oblique flow field, such as twin-propeller ship. Due to the influence of hull, the flow of the twin-propeller working disk in the sides of stern is non-uniform, so the propellers are always working in oblique flow. Additionally, in the process of ship maneuvering, the transverse velocity and turning speed of hull will also cause that propeller works in oblique flow. And then, when the ship backs up under certain rudder angle, the stern flow will form oblique flow because of the effect of rudder blade guiding flow. Through researching, it found that when the propeller work in oblique flow field, not only the thrust and torque will be affected in a certain degree, but also fiercer exciting force will be induced, including oblique flow transverse force which is against for ship maneuverability. It is necessary to research hydrodynamic performance of propeller and level of induced exciting force in detail and deeply in oblique flow.

This paper will be started with DTMB4679 propeller as the research object, and whose unsteady hydrodynamic performance in oblique flow will be calculated. Blade surface pressure and stress changes of single blade in the process of rotation will be emphatically analyzed, and will be compared with test value. The time-domain data of propeller exciting force under different working condition will be monitored, and then spectrum curve will be obtained through fast Fourier transform (FFT). Finally, the influence of advance coefficient and oblique flow angle to propeller exciting force under oblique flow condition will be summarized.

\section{Mathematic models}

\subsection{Governing equations}

Fluid flow is governed by physical conservation laws. Basic conservation laws include law of conservation of mass, law of conservation of momentum and law of conservation of energy. As the medium in our calculation, water, is an incompressible fluid whose heat exchange is little enough to ignore, only the mass conservation equation and the momentum conservation equation are solved. The mass conservation equation is shown in Eq. 1. And the momentum conservation equation is shown in Eq. 2 [7]. 
$\frac{\partial \rho}{\partial t}+\frac{\partial}{\partial x_{j}}\left(\rho u_{j}\right)=0$

where, $\rho$ is the liquid density and $u_{j}$ is the velocity vector. $u_{j}$ is the instantaneous value of velocity in $j$ direction.

$\frac{\partial(\rho u)}{\partial t}+\operatorname{div}(\rho u \vec{u})=-\frac{\partial p}{\partial x}+\frac{\partial \tau_{x x}}{\partial x}+\frac{\partial \tau_{y x}}{\partial y}+\frac{\partial \tau_{z x}}{\partial z}+F_{x}$

$\frac{\partial(\rho v)}{\partial t}+\operatorname{div}(\rho v \vec{u})=-\frac{\partial p}{\partial y}+\frac{\partial \tau_{x y}}{\partial x}+\frac{\partial \tau_{y y}}{\partial y}+\frac{\partial \tau_{z y}}{\partial z}+F_{y}$

$\frac{\partial(\rho w)}{\partial t}+\operatorname{div}(\rho w \vec{u})=-\frac{\partial p}{\partial z}+\frac{\partial \tau_{x z}}{\partial x}+\frac{\partial \tau_{y z}}{\partial y}+\frac{\partial \tau_{z z}}{\partial z}+F_{z}$

In Eq. 2, $P$ is the pressure of fluid element, $\tau_{x x}, \tau_{x y}, \tau_{x z}$ are the components of viscous stress $\tau$ on the surface of fluid element, and $F_{x}, F_{y}, F_{z}$ are the mass forces on fluid element.

\subsection{Turbulence model}

The turbulence model for our calculation is an SST $k-\omega$ model. It is frequently used in calculating propeller hydrodynamic performance. This model effectively integrates the merits of both $k-\varepsilon$ and $k-\omega$ models and can well simulate complex flows in the presence of flow separation and strong adverse pressure gradients. Its closed equations are shown in Eq. 3.

$\frac{\partial}{\partial t}(\rho k)+\frac{\partial}{\partial x_{i}}\left(\rho k u_{i}\right)=\frac{\partial}{\partial x_{j}}\left(\Gamma_{k} \frac{\partial k}{\partial x_{j}}\right)+G_{k}-Y_{k}+S_{k}$

$\frac{\partial}{\partial t}(\rho \omega)+\frac{\partial}{\partial x_{i}}\left(\rho \omega u_{i}\right)=\frac{\partial}{\partial x_{j}}\left(\Gamma_{\omega} \frac{\partial \omega}{\partial x_{j}}\right)+G_{\omega}-Y_{\omega}+S_{\omega}$

where, $G_{k}, G_{\omega}$ are the turbulence kinetic energy production items, $Y_{k}, Y_{\omega}$ are the turbulence dissipative items, and $S_{k}, S_{\omega}$ are the source items.

But there is certain requirement for the value of $Y^{+}$, and it is generally believed that about 60 is an appropriate value. Function definition of $Y^{+}$is shown in Eq. 4. It represents the dimensionless distance between the first layer of grid nodes and wall.

$Y^{+}=\frac{Y}{\mu} \sqrt{\rho \tau_{\omega}}$

Table 1 Main geometric parameters of DTMB 4679 propeller

\begin{tabular}{ll}
\hline DTMB 4679 propeller & \\
\hline Diameter $(\mathrm{mm})$ & 607 \\
Boss ratio & 0.3 \\
Number of blades & 3 \\
Area ratio $\left(A_{\mathrm{e}} / A_{0}\right)$ & 0.9 \\
Skew angle $\left(^{\circ}\right)$ & 50 \\
\hline
\end{tabular}

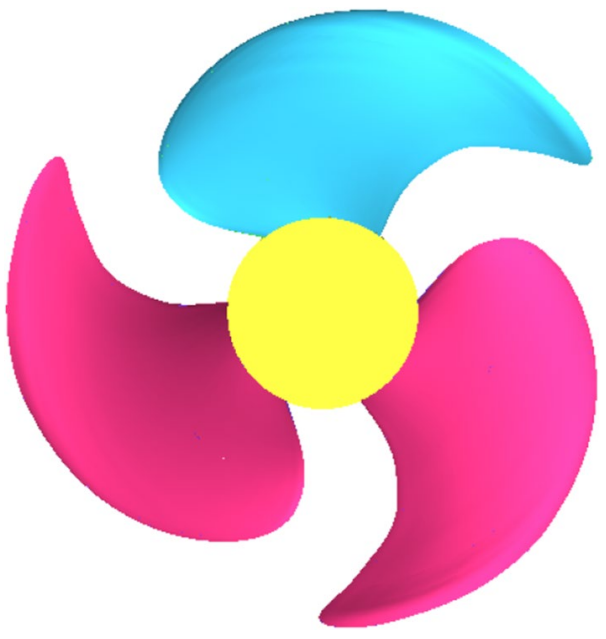

Fig. 1 geometric model of DTMB 4679 propeller

Here, $Y$ is the distance of unit center to wall, $\mu$ is the kinetic viscosity of a fluid, $\rho$ is the fluid density, and $\tau_{m}$ is the wall shear stress.

\section{Numerical setup}

\subsection{Test model}

Our calculation model is DTMB 4679 propeller. Its main geometric parameters [8] are shown in Table 1, and geometric model is shown in Fig. 1. American Taylor Tank has carried out some experimental study for this propeller under various working conditions, including the propeller performance test in oblique flow. It provided valuable test data for verifying the numerical calculation method of this paper. It was also the standard propeller of $22 \mathrm{nd}$ ITTC Propulsion Committee Proceedings of Propeller

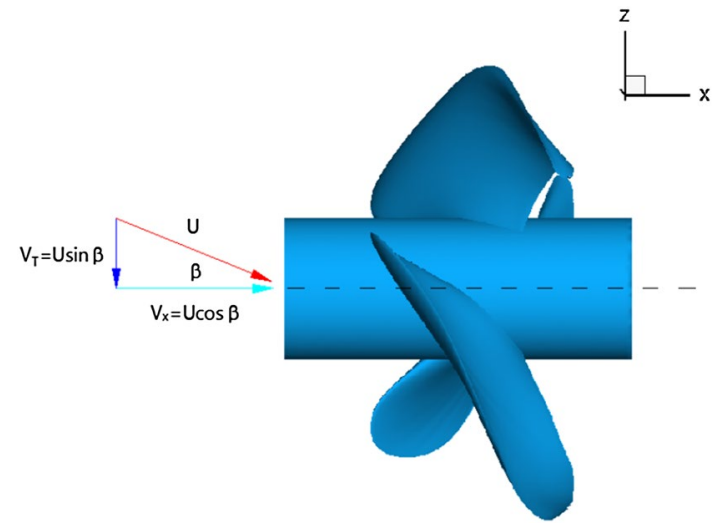

Fig. 2 Diagram of oblique flow coming 
RANS/Panel Method Workshop [9]. The calculation working conditions are shown in Table 2. Because the open water performance of propeller is irrelevant to coming direction of oblique flow, and only relates to angle magnitude. Thus, only the conditions of positive oblique flow angle need to be calculated.

To simulate the oblique flow, two methods can be applied. One is to adjust angle of propeller model, another one is to change coming flow velocity component. This paper applies the latter. Its benefit is that only one calculation model needs to be established to calculate whether working condition of no oblique flow angle or working condition of random oblique flow angles. And it saves a lot of workload. The coming flow of inlet is shown in Fig. 2.

\subsection{Establishment of computational domain and setting of computational parameters}

The CFD commercial software FLUENT was used to solve RANS equations using the SST model. The computational domain, described in Fig. 3, together with the boundary conditions, was defined so that the same grid could be used for all the oblique inflow angles by changing the imposed velocity components at the appropriate inlet boundaries. The front surface, left side and right side are all defined as velocity inlet to better simulate oblique flow. The front inlet is $4 D$ far from propeller center. The outlet is $6 D$ far from propeller center. The section area of front inlet is $4 D^{*} 4 \mathrm{D}$. $D$ is the propeller diameter.

The computational domain is composed of two zones. One is the cylinder wrapping propeller which is used to simulate propeller rotation, and the other one is the cuboid which is used to simulate the state of open water. There are two approaches to simulate propeller rotation. This cylinder

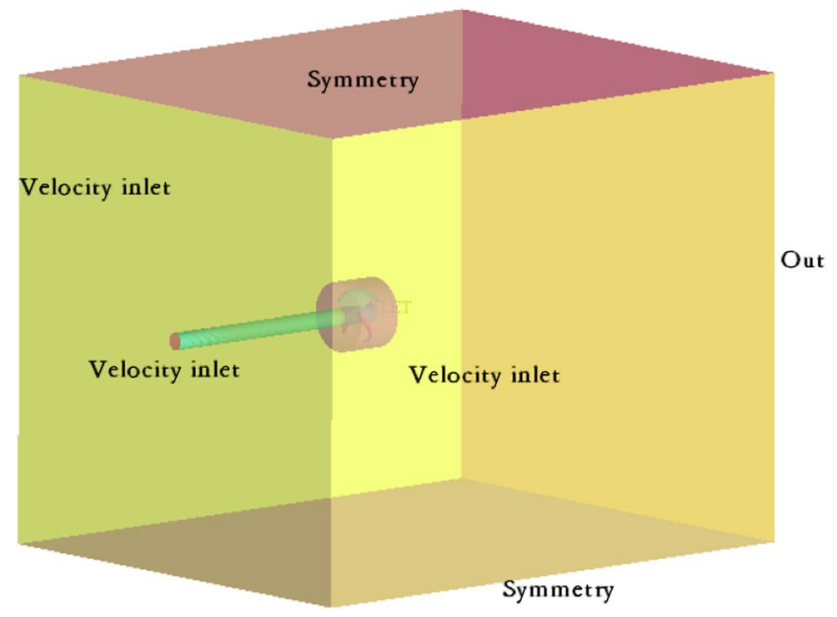

Fig. 3 Calculation domain of oblique flow fluid zone can rotate together with the propeller with a constant speed, or it can be defined as a relative reference frame in which the non-inertial equations of motion are solved in terms of the relative velocity. These two different approaches are, respectively, called sliding mesh technique and multi reference frame (MRF) method [10]. The MRF method is mainly applied for steady calculation. In this paper, the MRF was used first to save the computational efforts, as its calculation require is less than sliding mesh, and to have an initial result of the flow field for the following transient calculations with the sliding mesh technique. Moreover, to get the unsteady exciting force, the sliding mesh technique was used. In the unsteady calculation, the time step $1.69 \mathrm{E}-03$ was chosen, which is equivalent to $5^{\circ}$ of propeller rotation. The internal domain wrapping propeller rotates in speed of 492 RPM (The rotation speed is same as its speed in cavitation tunnel model test.) around the $X$-axis rotation. The external domain is absolutely static. Through changing coming flow velocity, we can get propeller hydrodynamic performance in different advance coefficients.

SIMPLEC algorithm is chose to solve the coupled equations of pressure and velocity [11]. For the method of spatial discretization, pressure is standard, and momentum is second-order upwind. The propeller blades, hub and outside wall of far field are all defined as non-slip wall. Inlet is set as velocity inlet, including front inlet, left side inlet, and right side inlet. The top and bottom of external domain are set as symmetry. Outlet is set as pressure outlet. Gauge pressure is set as 0 . The link of two domains is through interfaces. The flow field information transfer is through interface interpolation.

\subsection{Numerical grids}

CFD pre-processor ICEM CFD was used to divide computational domain grids. The hybrid grids are used which are composed of non-structured grids around propeller and structured grids of external domain. Because the propeller model is high-skew propeller, it is difficult to divide structured grids, and the quality of grids will be poor. So the rotation domain is divided into tetrahedral non-structured grids which have stronger geometric adaptability. From Fig. 4 a, some parts of large curvature change should be made local refinement, such as leading edge, trailing edge and blade root. Additionally, to better simulate the boundary layer, there are 8 layers of prismatic grids on the surface of blades and hub. From Fig. 4b, the thickness of the first layer of grids is $0.2 \mathrm{~mm}$, corresponding to whose $\mathrm{Y}^{+}$is about 60 . When advance coefficient is 1.078 , the propeller thrust coefficients and torque coefficients were calculated with different $\mathrm{Y}^{+}$. From the Fig. 5, it was shown that the propeller thrust coefficient changes little from $\mathrm{Y}^{+}=20$ to $\mathrm{Y}^{+}=60$, but there are greater changes 


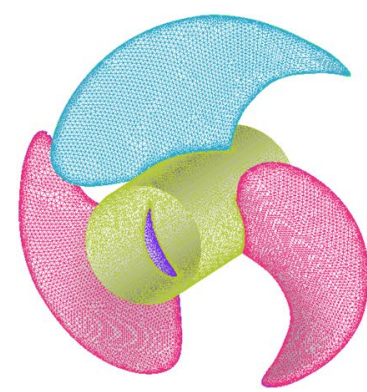

a Grids on blades surface

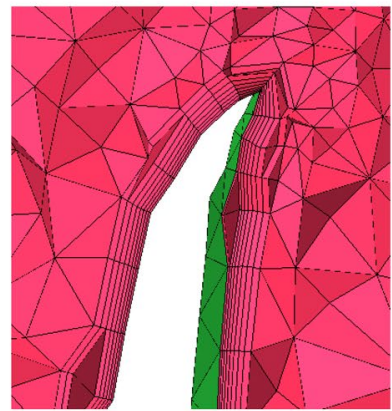

b Boundary layer grids

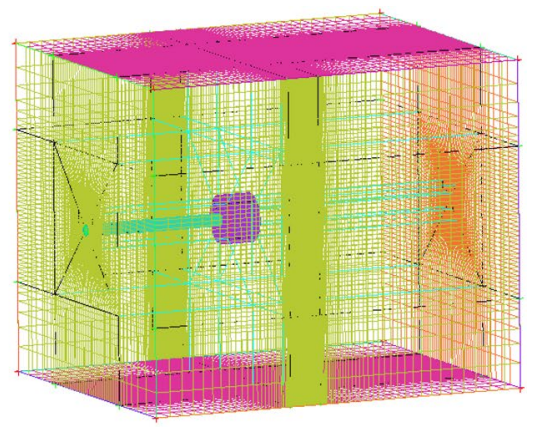

c External domain grids

Fig. 4 Calculation grids

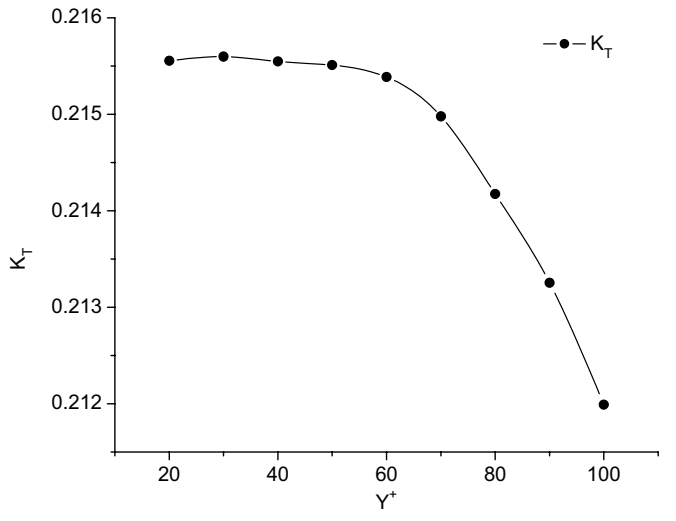

a The results of thrust coefficients with different $\mathrm{Y}^{+}$

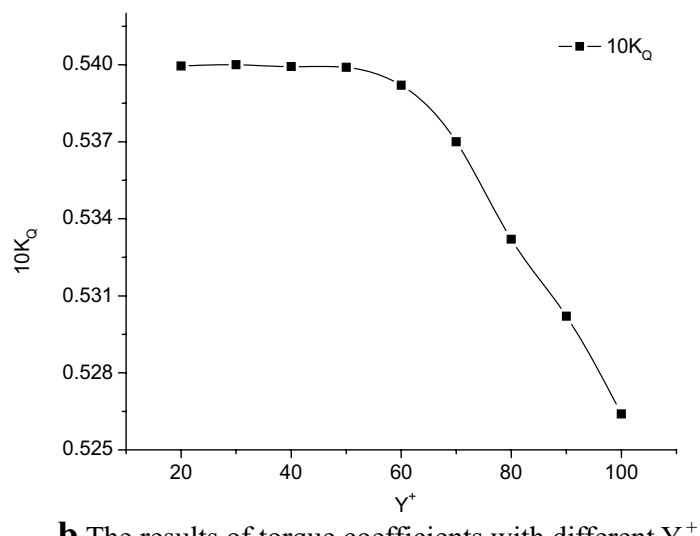

b The results of torque coefficients with different $\mathrm{Y}^{+}$

Fig. 5 Curves of grids convergence analysis

Table 2 Calculation working conditions of DTMB 4679 propeller

\begin{tabular}{lllll}
\hline & $\begin{array}{l}\text { Working condi- } \\
\text { tion 1 }\end{array}$ & $\begin{array}{l}\text { Working condi- } \\
\text { tion 2 }\end{array}$ & $\begin{array}{l}\text { Working condi- } \\
\text { tion 3 }\end{array}$ & $\begin{array}{l}\text { Working } \\
\text { condi- } \\
\text { tion } 4\end{array}$ \\
\hline Advance coefficient $J$ & 1.078 & 1.078 & 1.078 & 0.719 \\
Coming flow velocity $U(\mathrm{~m} / \mathrm{s})$ & 5.39 & 5.39 & 5.39 & 3.60 \\
Oblique flow angle $\beta\left(^{\circ}\right)$ & 0 & 7.5 & 15 & 7.5 \\
Rotating speed $(\mathrm{rps})$ & 8.20 & 8.20 & 8.20 & 8.21 \\
\hline
\end{tabular}

from $\mathrm{Y}^{+}=60$ to $\mathrm{Y}^{+}=100$. So it was proved that $\mathrm{Y}^{+}=60$ was appropriate through the grids convergence analysis. The external domain applies hexahedral structured grids to save number of grids. From Fig. 4c, the grids of flow field around propeller are appropriately refined, while far field grids are relatively sparse. Total calculation grids are about 3.24 millions.
Table 3 Steady thrust and torque of DTMB 4679 propeller $(J=1.078)$

\begin{tabular}{lllll}
\hline & $\begin{array}{l}\text { Thrust } \\
T(\mathrm{~N})\end{array}$ & $\begin{array}{l}\text { Torque } \\
Q(\mathrm{~N} \mathrm{~m})\end{array}$ & $\begin{array}{l}\text { Thrust coef- } \\
\text { ficient } K_{T}\end{array}$ & $\begin{array}{l}\text { Torque } \\
\text { coefficient } \\
10 K_{Q}\end{array}$ \\
\hline $\begin{array}{c}\text { Calculation } \\
\text { results } \beta=0^{\circ}\end{array}$ & 1960.5 & 298.6 & 0.2152 & 0.5399 \\
\hline
\end{tabular}




\section{Analysis of calculation results}

\subsection{Hydrodynamic performance}

\subsubsection{Analysis of open water performance}

Before calculating unsteady hydrodynamic performance of propeller in oblique flow, the rationality of calculation method and grids number is verified through steady calculation in working condition1 (See Table 2). When advance coefficient is 1.078 , the calculation results of steady thrust coefficient and torque coefficient are shown in Table 3. The results are used to compare with the calculation results in oblique flow.

Contrasting calculation results of pressure coefficient distribution with test results in sections of $0.7 \mathrm{R}$ and $0.9 \mathrm{R}$ is shown in Fig. 6. And pressure coefficient is defined as follows:

$C_{P}=\frac{P-P_{0}}{\frac{1}{2} \rho V_{\mathrm{R}}^{2}}$

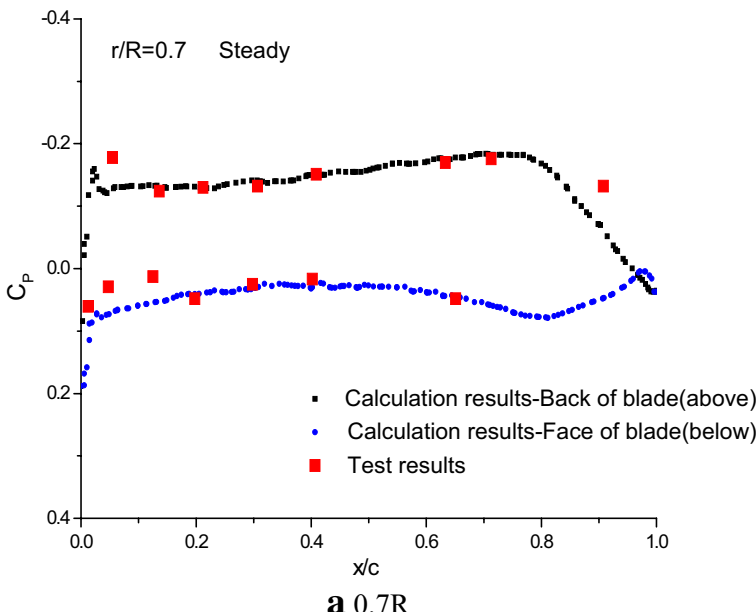

where, $\left(P-P_{0}\right)$ is the relative pressure, and the equation of relative inflow velocity is $V_{\mathrm{R}}=\sqrt{V_{\mathrm{x}}^{2}+(2 \pi n r)^{2}}$. Here, $V_{\mathrm{x}}$ is the axial velocity component, and $n$ is the speed of rotation. In Fig. 6, it shows that calculation results of pressure distribution agree well with the test results [12]. Especially, in central area of blade, the two results are almost consistent. It can indicate that the numerical calculation method can simulate accurately the pressure distribution of blade surface of high-skew propeller, and the grids number is also reasonable. However, the difference between calculated results and experimental results is concentrated in some measure points near leading edge and trailing edge. From Fig. 6a, there is a small pressure peak on the back of blade near leading edge in test results. But it cannot be well simulated in numerical calculation.

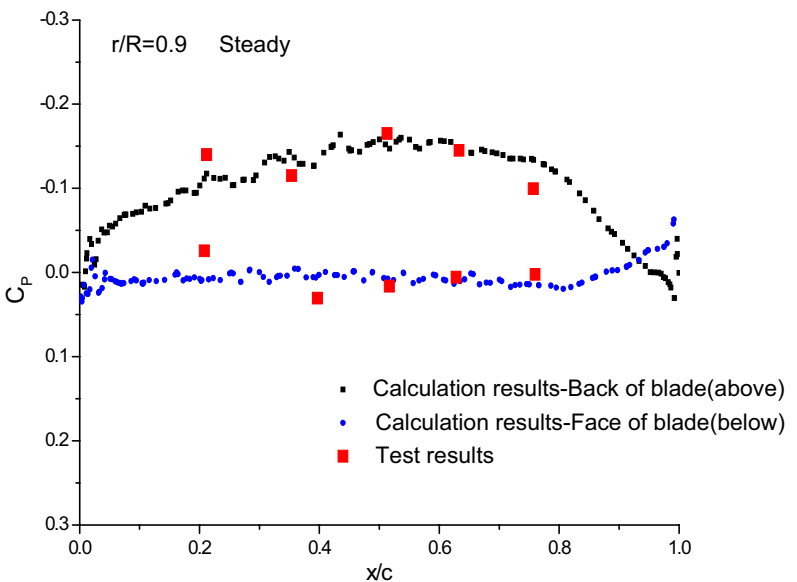

b $0.9 \mathrm{R}$

Fig. 6 Steady pressure coefficient distribution of sections in different radius $(J=1.078)$

Table 4 Time-averaged values of thrust and torque of DTMB 4679 propeller $(J=1.078)$

\begin{tabular}{lllll}
\hline & Thrust & Torque $Q(\mathrm{~N} \mathrm{~m})$ & \multicolumn{2}{c}{ Thrust coefficient } \\
& $T(\mathrm{~N})$ & & $\begin{array}{l}\text { Torque coefficient } \\
10 K_{Q}\end{array}$ & 0.5399 \\
\hline Steady calculation results $\beta=0^{\circ}$ & 1960.5 & 298.6 & 0.2152 & 0.5539 \\
Unsteady time-averaged values $\beta=7.5^{\circ}$ & 2014.3 & 306.4 & 0.2211 & 0.5507 \\
Literature [11] results (RANS) & - & - & 0.2294 & - \\
Literature [12] results (RANS) & - & - & $+2.71 \%$ & $+2.56 \%$ \\
Variation value of $\beta=7.5^{\circ}$ relative to $\beta=0^{\circ}$ & +53.8 & +7.8 & $4.29 \%$ & $0.57 \%$ \\
Relative error with the literature [11] & - & - & $3.68 \%$ & - \\
Relative error with the literature [12] & - & - & \\
\hline
\end{tabular}




\subsubsection{Analysis of unsteady calculation results under the oblique flow}

The angle between coming flow and shaft is adjusted to $7.5^{\circ}$, the unsteady hydrodynamic performance of propeller is, respectively, calculated when advance coefficients are 1.078 and 0.719 .

Through analyzing the data of Table 4, it can be known that thrust coefficient and torque coefficient have a certain degree of growth in oblique flow $\left(\beta=7.5^{\circ}\right)$ which are, respectively, 2.71 and $2.56 \%$ relatively to the results of axial flow. It shows that propeller load will increase in oblique flow. Additionally, the calculation results of RANS method from the literature $[13,14]$ are also listed in
Table 4. It can be seen that thrust calculation results in this paper are closer with the calculation results of the literature [14]. Relative error is $3.68 \%$. But comparing with the literature [13], relative error of thrust is $4.29 \%$, and relative error of torque is $0.57 \%$. The error of thrust value is within $5 \%$, and the two torque values are almost consistent. Generally, the calculation results in this paper are accurate and credible.

In Table 5, it shows that calculation results also agree well with results of the literature in $J=0.719$ condition.

To analyze stress distribution of single blade in the process of rotation more clearly, the hydrodynamic analysis of blade section 1 and blade section 2 are shown in Fig. 7. And the circumferential position of blade just facing transverse
Table 5 Time-averaged values of thrust and torque of DTMB 4679 propeller $(J=0.719)$

\begin{tabular}{lllll}
\hline & $\begin{array}{l}\text { Thrust } \\
T(\mathrm{~N})\end{array}$ & $\begin{array}{l}\text { Torque } \\
Q(\mathrm{~N} \mathrm{~m})\end{array}$ & $\begin{array}{l}\text { Thrust coefficient } \\
K_{T}\end{array}$ & $\begin{array}{l}\text { Torque coefficient } \\
10 K_{Q}\end{array}$ \\
\hline Unsteady time-averaged values $\beta=7.5^{\circ}$ & 3568.1 & 470.1 & 0.3916 & 0.8500 \\
Literature [11] results (RANS) & - & - & 0.376 & 0.837 \\
Literature [12] results (RANS) & - & - & 0.3822 & - \\
Relative error with the literature [11] & - & - & $4.06 \%$ & $1.54 \%$ \\
Relative error with the literature [12] & - & - & $2.430 \%$ & - \\
\hline
\end{tabular}

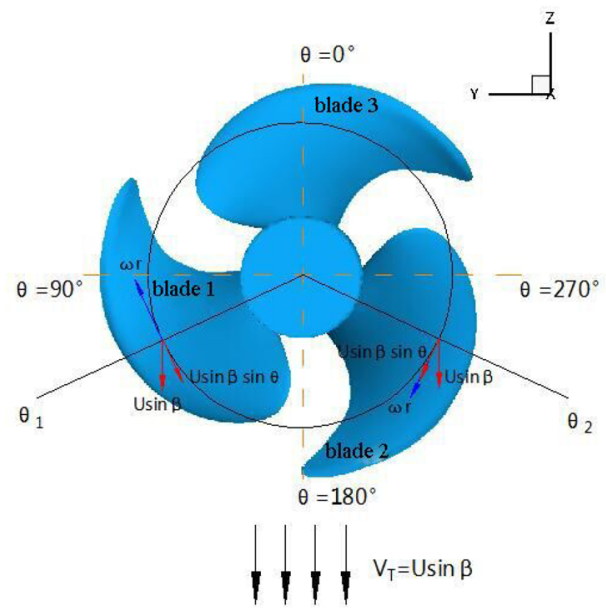

a Definition of blade angle and diagram of transverse flow

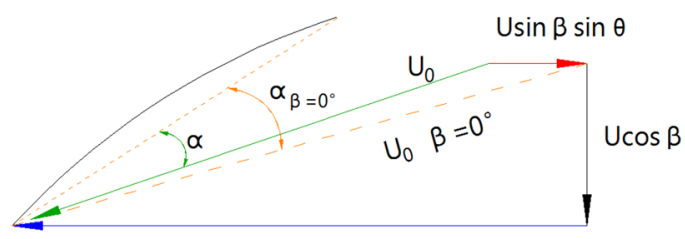

$\omega r$

b Velocity polygon of Bladel section

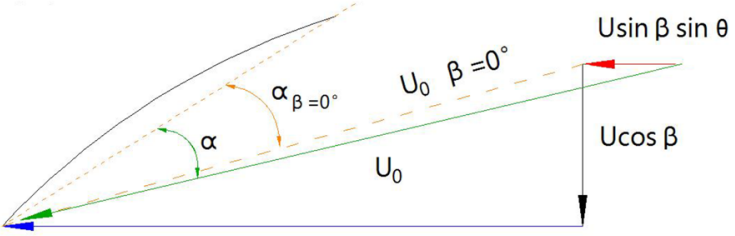

$\omega r$

c Velocity polygon of Blade2 section

Fig. 7 Hydrodynamic analysis of blade section in oblique flow 
coming flow is defined as $\theta=0^{\circ}$. The angle increases in turn according to anticlockwise direction. The coming flow of blade section includes mainly axial velocity component $V_{x}$ and circumferential velocity component $V_{t}$. It can be defined as follows:

$V_{x}=U \cos \beta$

$V_{t}=\omega r-U \sin \beta \sin \theta$

Here, $U$ is the oblique flow velocity, $\omega$ is the propeller rotation angular velocity, $\beta$ is the oblique flow angle, and $\theta$ is the circumferential position of blade. Under not considering the propeller self-induced velocity, axial velocity component $V_{x}$ is constant in the process of blade rotating a round. That is, axial velocity component $V_{x}$ is uniform and symmetrical on propeller disk. And its influence to thrust and torque is same in every quadrant. However, circumferential velocity component $V_{t}$ is different. It is the main reason of propeller generating unsteady force. For a position in particular radius, circumferential velocity $\omega r$ of blade rotation is definite. But $-U \sin \beta \sin \theta$ is constantly changing in the process of rotating a round because of the change of circumferential position angle $\theta$. It results in constant change of angle of attack of blade section:

$\alpha=\Theta-\arctan \left(\frac{V_{x}}{V_{t}}\right)$

Here, $\Theta$ is the pitch angle of blade section. In Eq. 8, it shows the larger axial velocity component, the larger angle of attack of blade section, and the larger blade thrust. The angle of attack of blade section under pure axial flow $\left(\beta=0^{\circ}\right)$ is shown in Figs. $6 \mathrm{~b}$ and $7 \mathrm{c}$. It can be seen that angle of attack of blade section in position of Blade1 is smaller than it under pure axial flow. But the angle of attack of blade section in

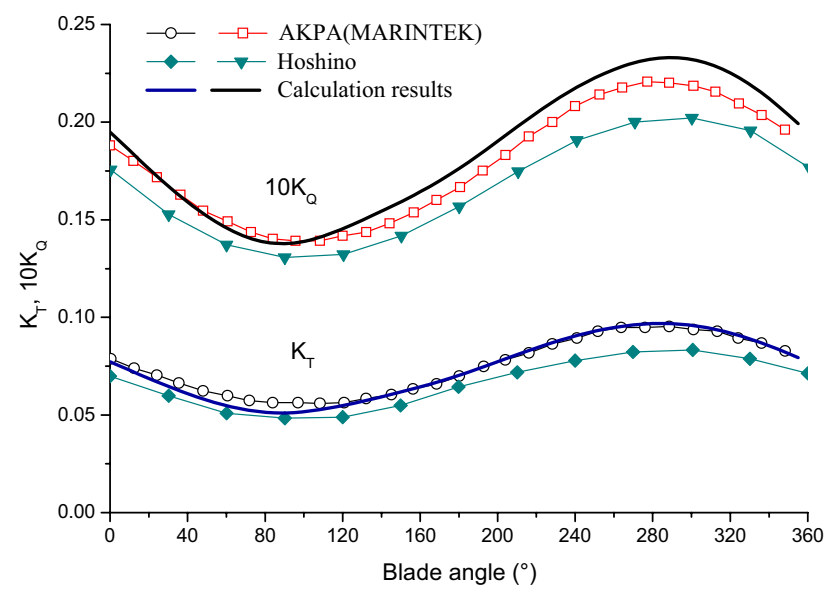

position of Blade3 is larger than it under pure axial coming flow. It can draw the following conclusions through comprehensive analysis: thrust and torque of blade is smallest when $\theta=90^{\circ}$, and torque of blade is largest when $\theta=270^{\circ}$. This is consistent with the calculation results in Fig. 8.

The curve of thrust and torque in the process of single blade rotating a round is shown in Fig. 8 when $J=1.078$. The calculation results of AKPA code of MARINTEK and the calculation results of Hoshino are also listed in Fig. 8. These results are provided to compare with the results of this paper. From Fig. 8, it can be seen that calculation results of thrust coefficients in this paper are almost consistent with the calculation results of AKPA code, and torque coefficients are basically consistent within $0^{\circ}$ to $120^{\circ}$. And the results of torque coefficients in this paper are slightly larger than other calculation results, but the relative error is within an acceptable range.

To research stress situation of blade in fluid more deeply, it is necessary to make a detailed discussion to pressure distribution of blade surface in oblique flow. In Fig. 9, the pressure prediction results of blade surface in the non-uniform flow field have a high precision, which agree well with test results. Errors mainly appear in leading edge $(x / c=0.0)$ and trailing edge $(x / c=1.0)$. The possible reasons are: first, while test is measuring, due to geometric shapes, setting measurement points near leading edge and trailing edge is more difficult than central part of blade, especially near blade tip, so test data will exist a certain error; second, to convenient grids division, the circle of calculation model in leading edge and trailing edge is simplified, so it has a bit difference from test model; third, velocity gradient is greater near blade tip, leading edge and trailing edge, and the change of pressure is more intense, so numerical simulation results easily appear large error.

\subsection{Analysis of propeller exciting force under different advance coefficients}

\subsubsection{Calculation results of bearing force}

After the unsteady calculation convergence is stability, timedomain data of six pulsating components of unsteady propeller bearing force starts to be monitored, including thrust, transverse force, vertical force, torque, transverse bending moment, and vertical bending moment. To compare differences and analyze rule of bearing force in different advance coefficients, all forces and moments are made dimensionless according to following formula:

$K_{T i}=\frac{T_{i}}{\rho n^{2} D^{4}}$

Fig. 8 Pulsating curve of torque coefficient and thrust coefficient of single blade $\left(\beta=7.5^{\circ}, J=1.078\right)$ 


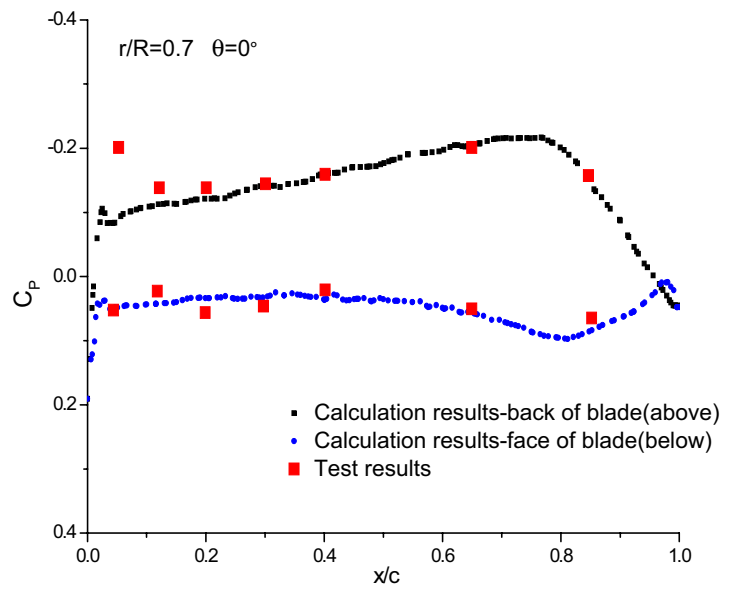

a Position $0^{\circ}$ and $0.7 \mathrm{R}(J=1.078)$

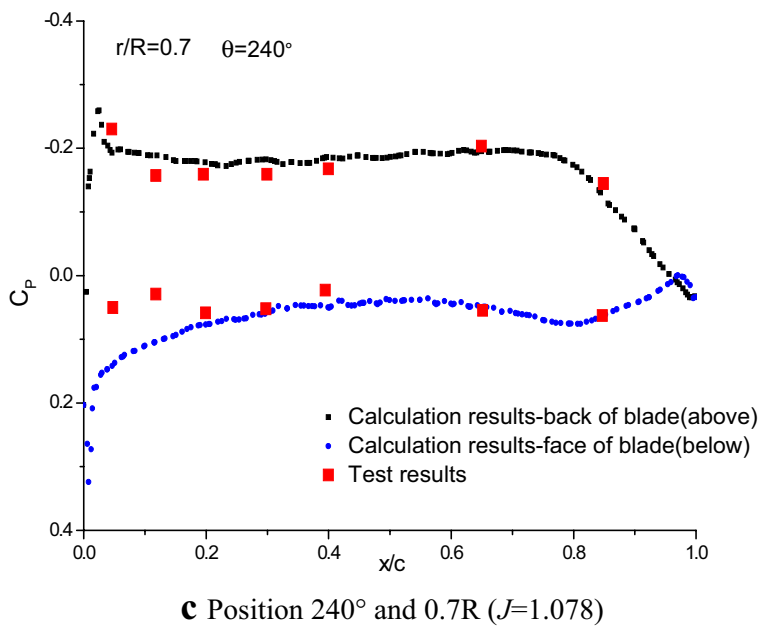

Fig. 9 Pressure coefficients distribution of blade section $\left(\beta=7.5^{\circ}\right)$

$$
K_{Q i}=\frac{Q_{i}}{\rho n^{2} D^{5}}
$$

Here, $i=x, y, z$ represent the reference axis, $\rho$ is the water density, $n$ is the rotation speed, and $D$ is the diameter of propeller. The data through being dimensionless is drawn a time-domain curve, and then the time-domain curve transforms into frequency-domain curve through FFT. The pulsating time-domain curve and frequency-domain curve of propeller bearing force is shown in Fig. 10 when $\beta=7.5^{\circ}$ and $J=1.078$. The pulsating time-domain curve and frequency-domain curve of propeller bearing force is shown in Fig. 11 when $\beta=7.5^{\circ}$ and $J=0.719$. Additionally, it needs to make a statement that negative direction of $X$-axis is set as the positive direction of thrust coefficient values, and the other values set the positive direction of coordinate system as their positive direction.

Through comparing the time-domain curves in Fig. 10, it can be seen that six components of unsteady propeller

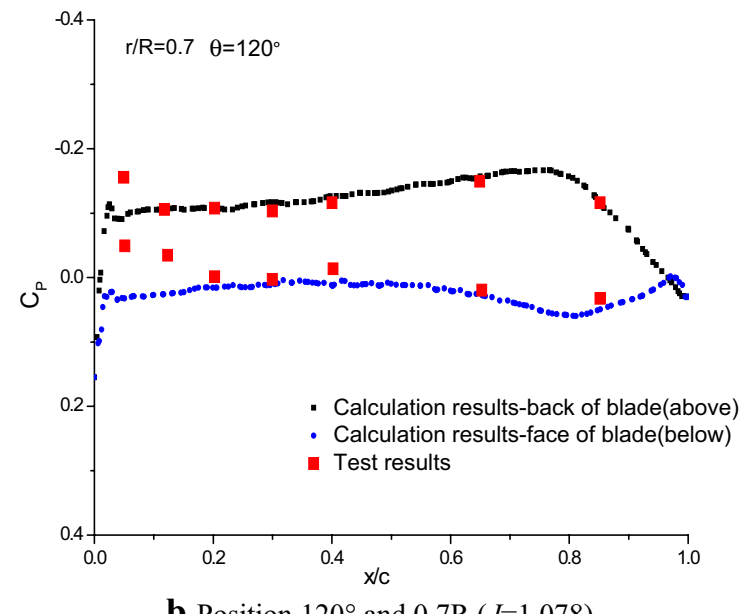

b Position $120^{\circ}$ and $0.7 \mathrm{R}(J=1.078)$

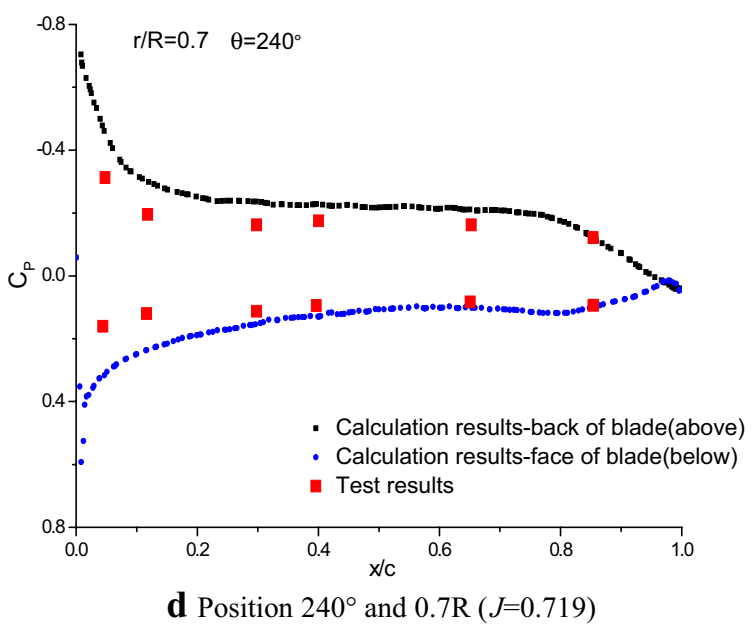

bearing force change periodically with time, and their pulsating cycle is the cycle of propeller rotation. It can be found that there is a certain phase difference between thrust and side force through comparing the two time-domain curve. The reason is that thrust is mainly affected by pressure field of blade surface, and side force is related to viscous effect of boundary layer on blade surface. So there is certain phase difference between the two in time response. It is also mentioned in the literature [15].

In the frequency-domain curve, it shows that their pulsating mainly frequency is blade frequency $(24.6 \mathrm{~Hz})$, duple blade frequency $(49.2 \mathrm{~Hz})$, and shaft frequency $(8.2 \mathrm{~Hz})$. The pulsating peak in blade frequency is largest, and pulsating amplitudes of other frequency can basically be neglected. At one same advance coefficient, from pulsating peak in blade frequency, the difference of bearing force components is not obvious, and pulsating peak values of vertical force and vertical bending moment are even greater than thrust and torque. It shows, although the time-average 
Fig. 10 Unsteady propeller bearing force $\left(\beta=7.5^{\circ}\right.$, $J=1.078$ )

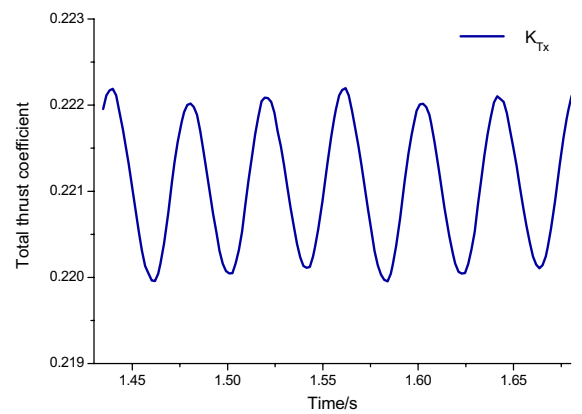

a Pulsating time-domain curve of total thrust coefficient $(J=1.078)$

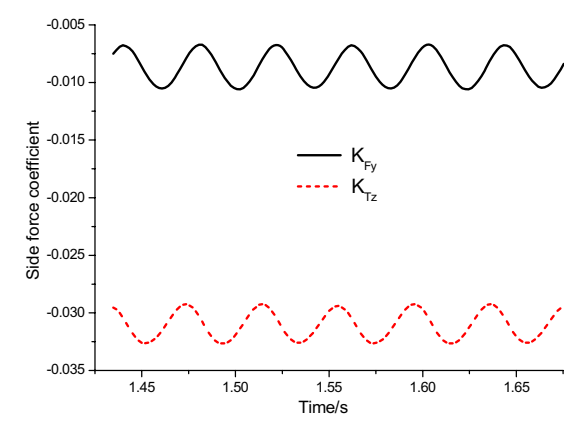

c Pulsating time-domain curve of side force coefficient ( $J=1.078$ )

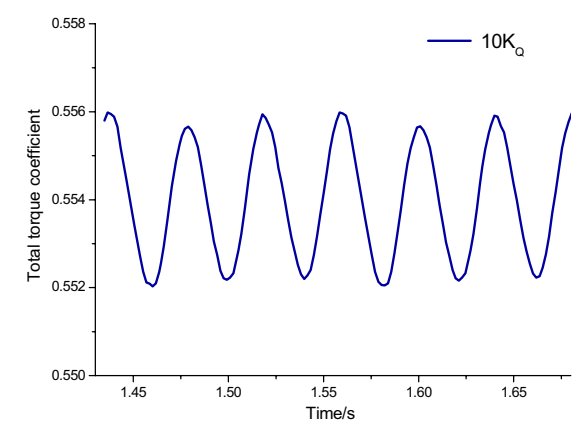

e Pulsating time-domain curve of total torque coefficient $(J=1.078)$

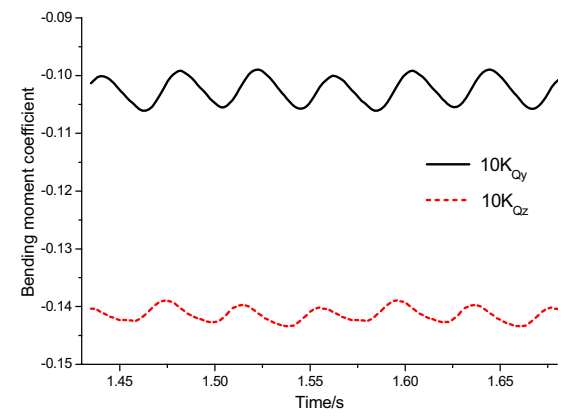

g Pulsating time-domain curve of bending moment coefficient $(J=1.078)$

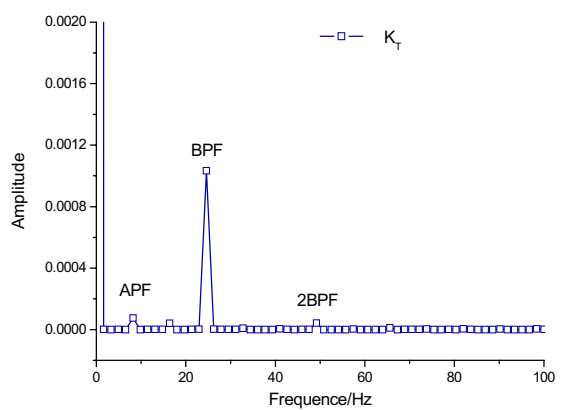

b Pulsating frequency-domain curve of total thrust coefficient $(J=1.078)$

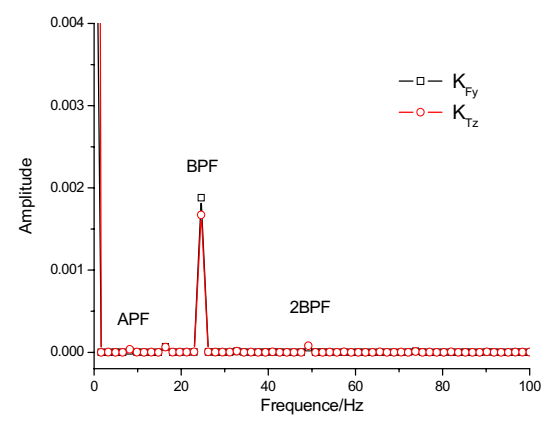

d Pulsating frequency-domain curve of side force coefficient $(J=1.078)$

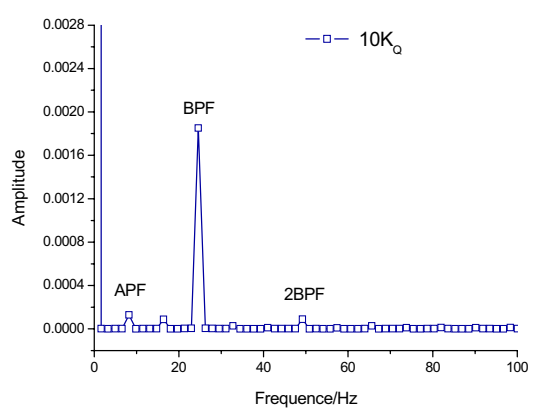

f Pulsating frequency-domain curve of total torque coefficient $(J=1.078)$

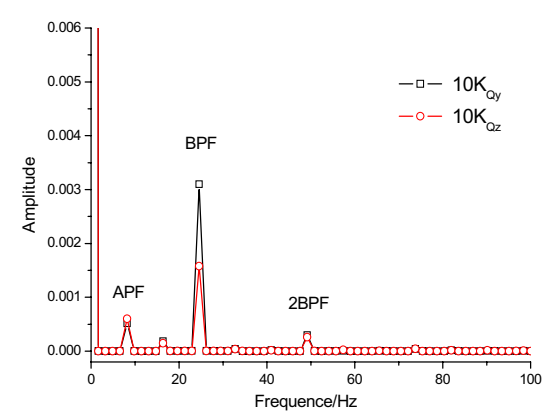

h Pulsating frequency-domain curve of bending moment coefficient $(J=1.078)$ 
Fig. 11 Unsteady propeller bearing force $\left(\beta=7.5^{\circ}\right.$, $J=0.719$ )

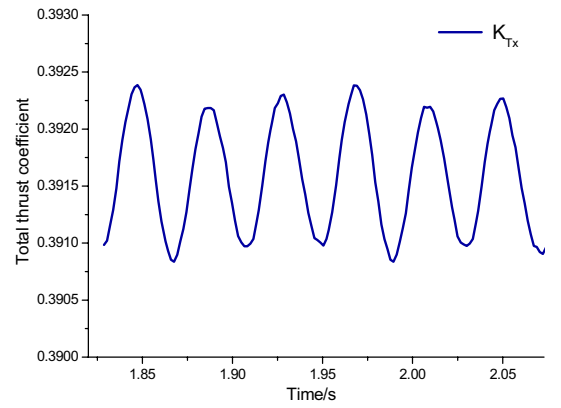

a Pulsating time-domain curve of total thrust coefficient $(J=0.719)$

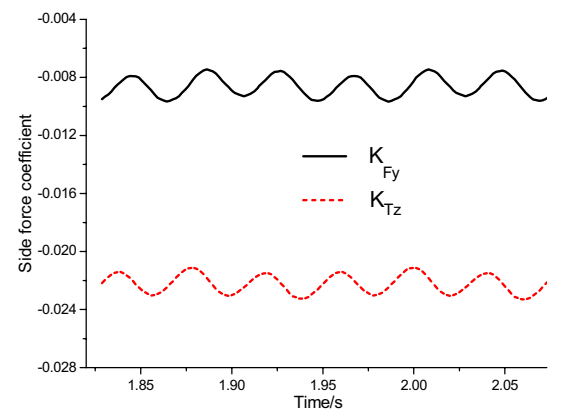

c Pulsating time-domain curve of side force coefficient ( $J=0.719$ )

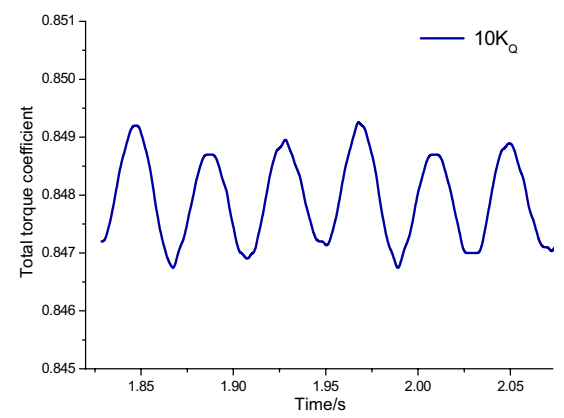

e Pulsating time-domain curve of total torque coefficient $(J=0.719)$

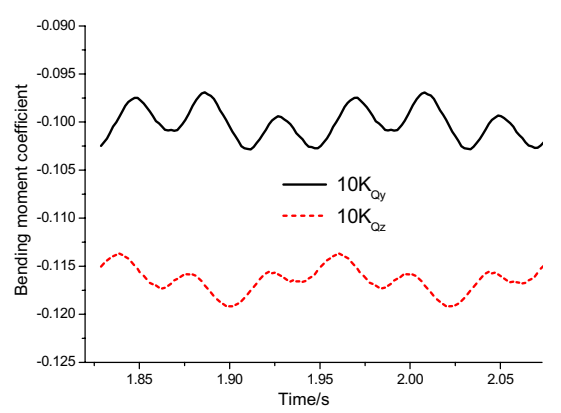

g Pulsating time-domain curve of bending moment coefficient $(J=0.719)$

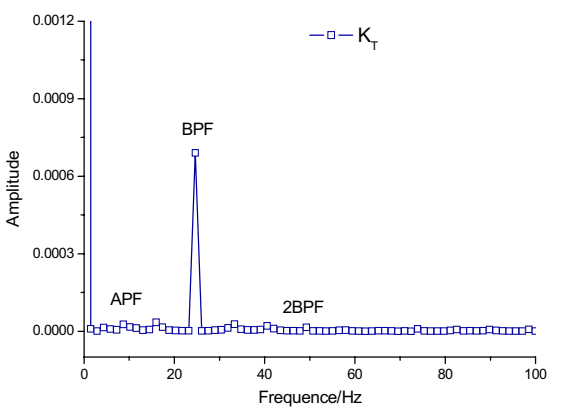

b Pulsating frequency-domain curve of total thrust coefficient ( $J=0.719$ )

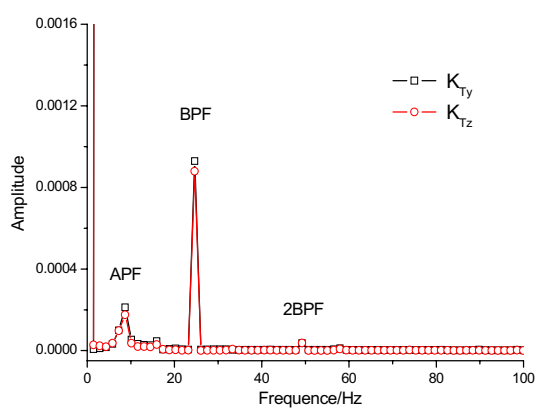

d Pulsating frequency-domain curve of side force coefficient ( $J=0.719$ )

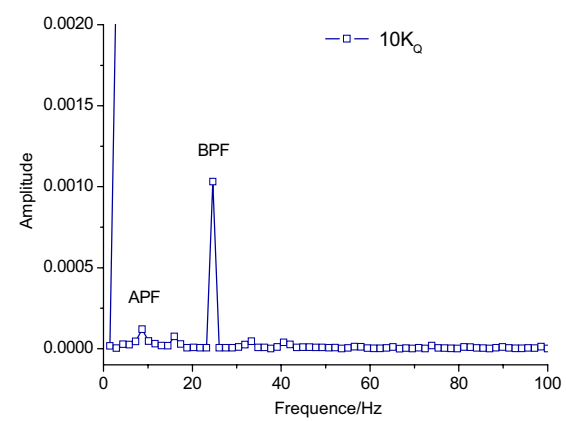

f Pulsating frequency-domain curve of total torque coefficient $(J=0.719)$

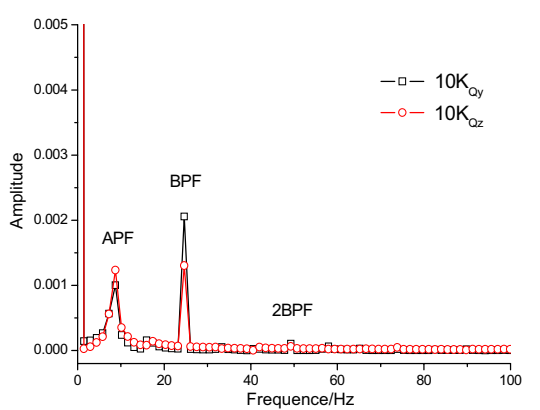

h Pulsating frequency-domain curve of bending moment coefficient $(J=0.719)$ 
values of side force and bending moment are less than thrust and torque, but their effect on propeller strength, hull strength, and hull vibration cannot be ignored.

To compare bearing force data at two different advance coefficients more clearly, time-average value in time-domain, peak of shaft frequency, peak of blade frequency and peak of duple blade frequency in frequencydomain are, respectively, drawn in histogram, as shown in Figs. 12 and 13.

Figure 12 shows the following rules:

1. At one advance coefficient, side force and bending moment comparing with thrust and torque are small amount, while transverse force and transverse bending moment is greater than vertical force and vertical bending moment. This is because vertical velocity in oblique flow is zero, and it leads to vertical force that the distribution of propeller induced velocity in propeller disk is non-uniform. But transverse velocity component in oblique flow will cause large transverse force generated by propeller, and the transverse force is called transverse force of propeller oblique flow effect [16] which has the important influence on ship maneuverability.

2. At one same oblique flow angle and different advance coefficients, thrust and torque in small advance coefficient are greater than the thrust and torque in large advance coefficient. The vertical force and vertical bending moment have little difference, and transverse force and transverse bending moment decrease with the decrease of advance coefficients. This is because the non-uniform degree of velocity field induced by propeller on propeller disk would not change too much with advance coefficient, so vertical forces and vertical bending moments in different advance coefficients are basically identical. However, along with advance coefficient decreasing, transverse velocity component in oblique flow also decreases. So it leads that transverse force and transverse bending moment in small advance coefficient is obviously smaller than that in larger advance coefficient.

Through analyzing the data in Fig. 13, it can be found that the percentage of pulsating value of thrust and torque in time-average value of thrust and torque is very small which is within $1 \%$. The reason is that the oblique flow is uniform wake field, so it does not like the non-uniform stern wake field where the percentage of pulsating value of thrust and torque in time-average value of thrust and torque will be greater. Meanwhile, it can indicate that highly

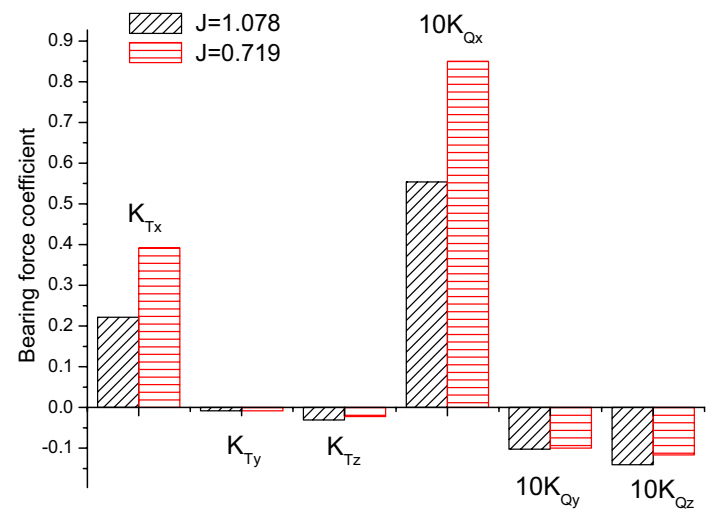

Fig. 12 Time-average value of unsteady bearing force coefficient $\left(\beta=7.5^{\circ}\right)$

skewed propeller can effectively decrease the pulsating amplitude of thrust and torque. Additionally, the influence of advance coefficient on pulsating peak of bearing force in shaft frequency, blade frequency and duple blade frequency shows totally that the larger advance coefficient, the higher pulsating peak in these frequencies. But the difference of individual unsteady force peak in the two advance coefficients is no obvious. And the trends in some frequencies are even opposite. It is considered that the difference of pulsating amplitude of bearing force caused by advance coefficient is not obvious, and the working conditions calculated in this paper are too little. Here, it is not suitable to make an exact conclusion on the relationship of advance coefficient and the pulsating amplitude of unsteady bearing force. Here, it provides the calculation results for reference only.

\subsubsection{The calculation results of fluctuating pressure}

A series of measure points in flow field around propeller are arranged to monitor the change of fluctuating pressure and the arrangement of measure points is shown in Fig. 14. P01, P0, P02 are located in a straight line above center of propeller. The distance between $\mathrm{P} 01$ and blade tip is $0.1 \mathrm{D}$, and the distances between $\mathrm{P} 01$ and $\mathrm{P} 0, \mathrm{P} 02$ and $\mathrm{P} 0$ are also 0.1D. P1, P2, P3, P4 and P0 are located in a plane above propeller. The distances between $\mathrm{P} 0$ and $\mathrm{P} 1, \mathrm{P} 0$ and $\mathrm{P} 2, \mathrm{P} 0$ and $\mathrm{P} 3, \mathrm{P} 0$ and $\mathrm{P} 4$ are all $0.1 \mathrm{D}$, and the vertical distances between blade tip and them are all 0.2D. To compare and analyze the difference and rule of fluctuating pressure in different advance coefficients, all amplitudes of fluctuating pressure are dealt with dimensionless method in the following equation: 


$$
K_{P}=\frac{P}{\rho n^{2} D^{2}}
$$

Here, $P$ is the amplitude of fluctuating pressure, $n$ is the rotation speed of propeller, $\rho$ is the water density, and $D$ is the propeller diameter.

The time-domain curve and frequency-domain curve of fluctuating pressure induced by propeller when $\beta=7.5^{\circ}$ and $J=0.719$ are shown in Fig. 15 .

Figure $15 \mathrm{a}, \mathrm{c}$ show that due to the rotation of propeller, there is certain phase difference between pulsating peaks of each point. There even appears that the position of crest corresponds to the position of trough among P0, $\mathrm{P} 2$ and $\mathrm{P} 4$, which are located in the different positions of

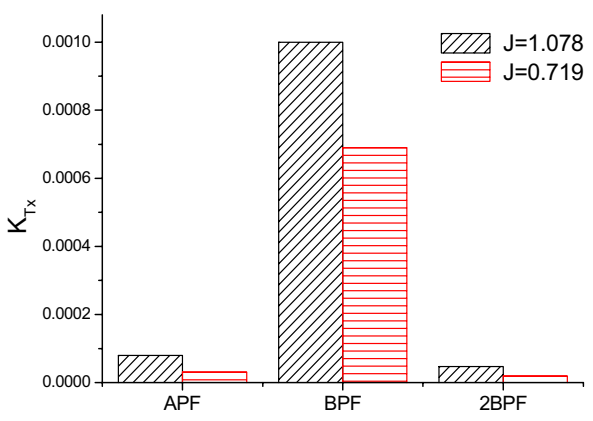

a Pulsating peak of thrust coefficient

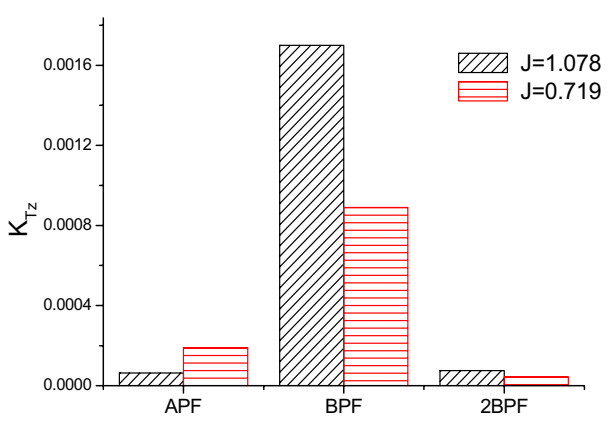

C Pulsating peak of transverse force coefficient

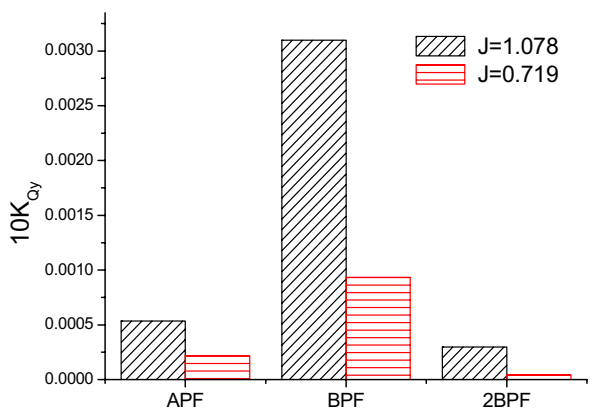

e Pulsating peak of vertical bending moment coefficient shaft direction. The pulsating form of P2 has slight difference from other points. This is mainly affected by flow behind propeller which makes pulsating form of pressure more complex.

In Fig. 15b, d, the peak of fluctuating pressure induced by propeller in oblique flow is most in blade frequency as well, and then decreases gradually to zero. It is worth noting that there does not appear the corresponding peak in duple blade frequency and multiple blade frequency. The frequency positions of peak appearing are all less than duple blade frequency and multiple blade frequency.

The time-domain curve and frequency-domain curve of fluctuating pressure in $\mathrm{P} 0, \mathrm{P} 01$ and $\mathrm{P} 02$ are shown in Fig. 15e, f. The time-domain curve shows that the pressure

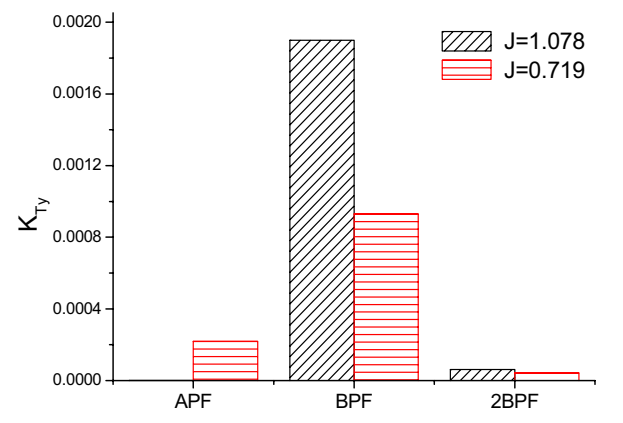

b Pulsating peak of vertical force coefficient

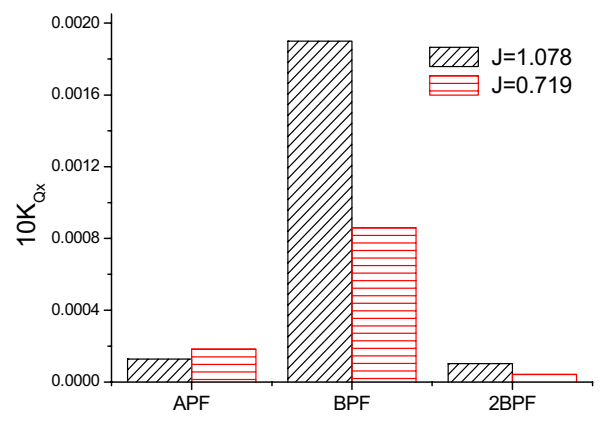

d Pulsating peak of torque coefficient

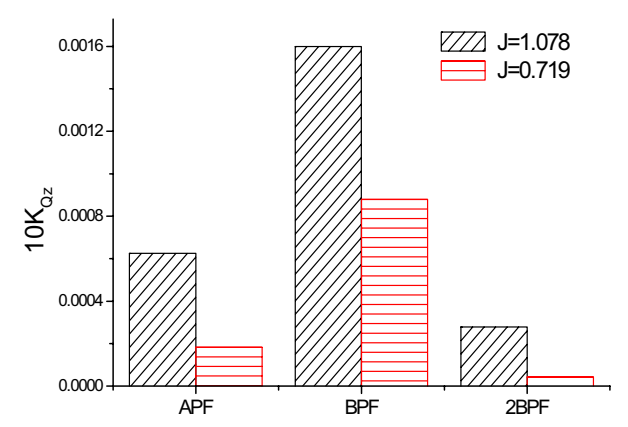

f Pulsating peak of transverse bending moment coefficient

Fig. 13 Comparison of bearing force pulsating peak under different advance coefficients $\left(\beta=7.5^{\circ}\right)$ 


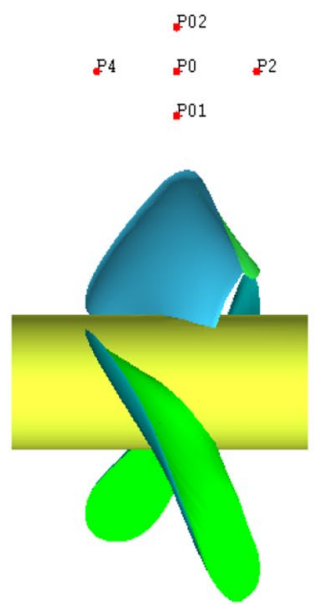

a Figure1 of arranging measure points

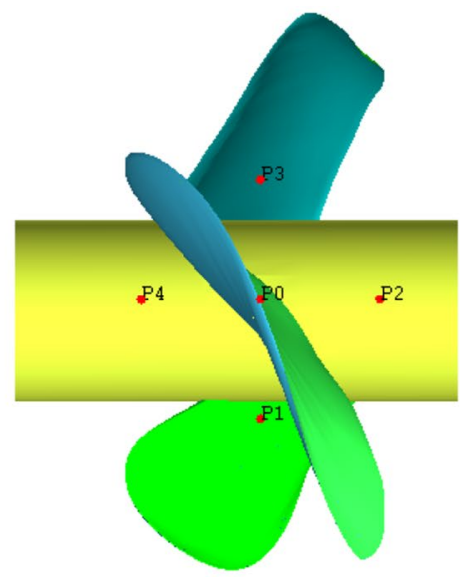

b Figure2 of arranging measure points

Fig. 14 Arrangement of measure points of fluctuating pressure induced by propeller

value of P01 which is closest to blade tip appears sharp pulsation with time, and the pulsating amplitude of $\mathrm{P} 01$ is much greater than the other two points. With the distance between measure point and blade tip increasing, pulsating range of pressure sharply decreases. At the same distance, pulsating difference between $\mathrm{P} 0$ and $\mathrm{P} 02$ is much less than that between $\mathrm{P} 0$ and $\mathrm{P} 01$. Because $\mathrm{P} 0$ and $\mathrm{P} 02$ are located in one perpendicular line, so their phases are consistent. From the frequency-domain curve, the distribution frequencies of pulsating peak of $\mathrm{P} 01$ are very wide, and the pulsating peak in blade frequency is not the biggest. The pulsating peaks of $\mathrm{P} 0$ and $\mathrm{P} 02$ are obvious only in blade frequency.

Generally speaking, pressure fluctuation value is inversely proportional to the distance between pulsating source and measure point [17]. The calculation results of this paper agree well with this conclusion. It indicates that the distance between blade tip and measure point makes the biggest effect to fluctuating pressure in the condition of no cavitation. The propeller of low rotation speed and large diameter has the characteristics of high efficiency and good vibration performance, but the increase of diameter will reduce the spacing between blade tip and stern. It leads to the increase of fluctuating pressure induced by propeller. So the diameter and the spacing of blade tip and stern must be made overall consideration during the actual use. Figure 16 is the frequency-domain curve of fluctuating pressure induced by propeller in different advance coefficients. It shows that peak of propeller fluctuating pressure in low advance coefficient is greater than the one in high advance coefficient.

\subsection{The calculation results of exciting force in different oblique flow angles}

Adjustment of oblique flow angle will change axial and transverse velocity components, and then change propeller exciting force. To research the influence of oblique flow angle on propeller exciting force, the calculation results of propeller exciting force in $\beta=7.5^{\circ}$ and $\beta=15^{\circ}$ are analyzed and compared, and the advance coefficients in this two conditions are both 1.078.

\subsubsection{The calculation results of bearing force}

The pulsating curve of thrust coefficient and torque coefficient in the process of single blade rotating a round at different oblique flow angles are shown in Fig. 17. It shows that along with oblique flow angle increasing, the circumferential positions of peaks and troughs of thrust and torque do not change. But according to the Eqs. 3-4, increasing of transverse velocity component will result in increasing of attack angle of blade section, and then make the pulsating range of thrust and torque of blade increasing. It is harmful for propeller exciting force.

The time-average values of unsteady bearing force under different oblique flow angles are shown in Fig. 18. After oblique flow angle change to twice as before, thrust coefficient and torque coefficient increase by about $10 \%$. But side force and side bending moment increase by times, their increase rate is basically consistent with the increase rate of oblique flow angle. The reason of bending moment increasing is that the acting direction 


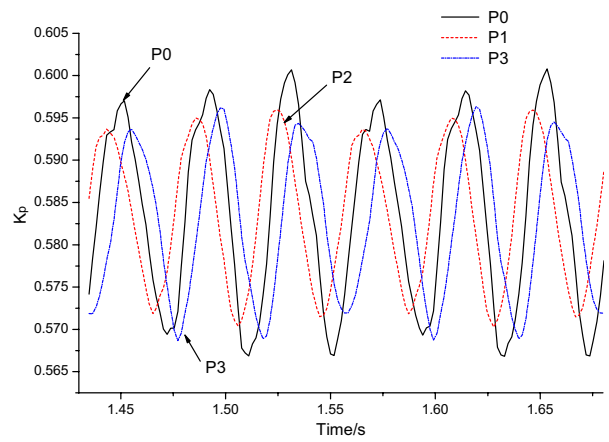

a Time-domain curve of fluctuating pressure coefficient of $\mathrm{P} 0, \mathrm{P} 1$ and $\mathrm{P} 3$

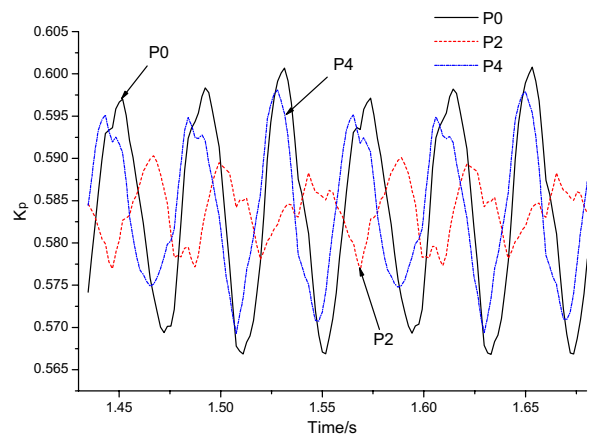

c Time-domain curve of fluctuating pressure coefficient of $\mathrm{P} 0, \mathrm{P} 2$ and $\mathrm{P} 4$

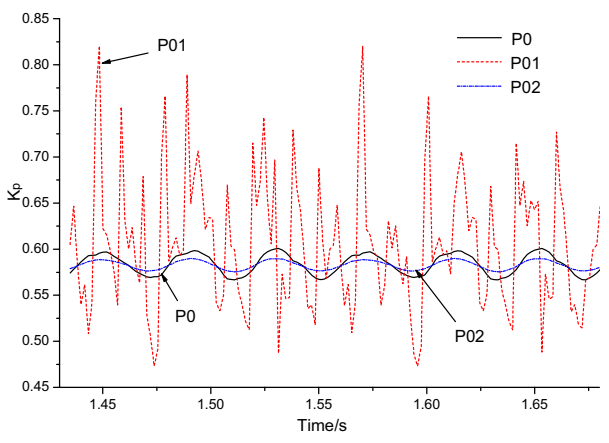

e Time-domain curve of fluctuating pressure coefficient of $\mathrm{P} 0, \mathrm{P} 01$ and $\mathrm{P} 02$

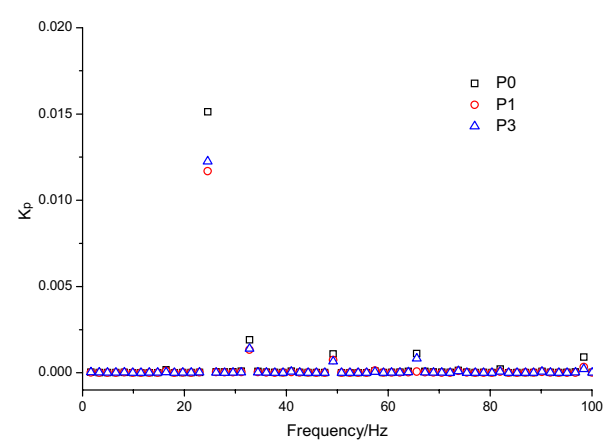

b Frequency-domain curve of fluctuating pressure coefficient of $\mathrm{P} 0, \mathrm{P} 1$ and $\mathrm{P} 3$

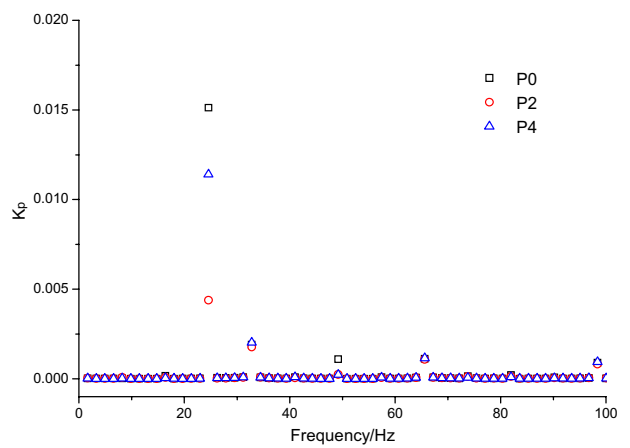

d Frequency-domain curve of fluctuating pressure coefficient of $\mathrm{P} 0, \mathrm{P} 2$ and $\mathrm{P} 4$

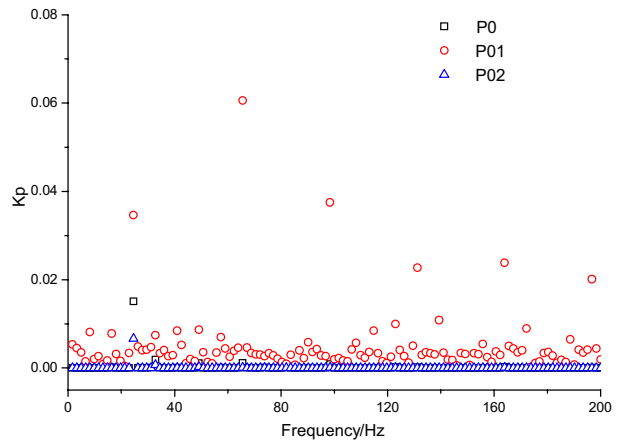

f Frequency-domain curve of fluctuating pressure coefficient of $\mathrm{P} 0, \mathrm{P} 1$ and $\mathrm{P} 2$

Fig. 15 Time-domain curve and frequency-domain curve of fluctuating pressure induced by propeller $\left(\beta=7.5^{\circ}, J=1.078\right)$

of resultant force of three blades deviates from shaft direction too much with oblique flow angle increasing. The reason of side force is that the vertical component and transverse component of rotation resistance acting on blade increase. It shows that the problem of propeller strength in large oblique flow angle should be paid more attention.

The pulsating peaks of unsteady bearing force coefficient at different oblique flow angles are shown in Fig. 19. Figure 19 shows that pulsating peaks of unsteady bearing force coefficient at large oblique flow angles increase generally, and the increase rate of pulsating peaks is faster than the increase rate of oblique flow angles. But the increase range of vertical bending moment and transverse bending moment is less than other unsteady components. The pulsation of bending moment has two main reasons: one is fluctuation of resultant force value of all blades thrust, the other one is fluctuation of resultant force acting direction [18]. The combined action of two reasons is likely to decrease the pulsating range. 


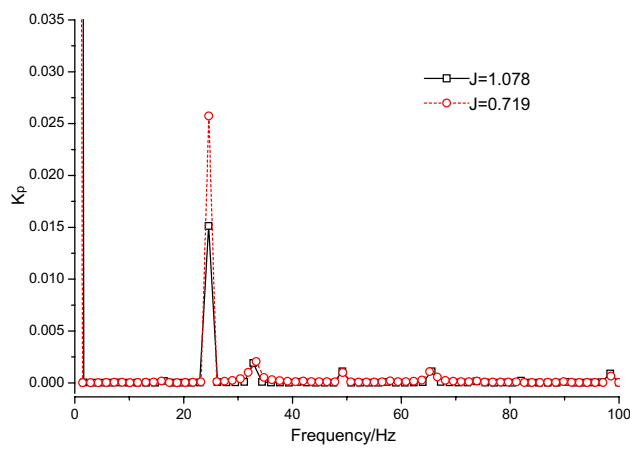

a Frequency-domain curve of fluctuating pressure coefficient of P0 under different advance coefficients

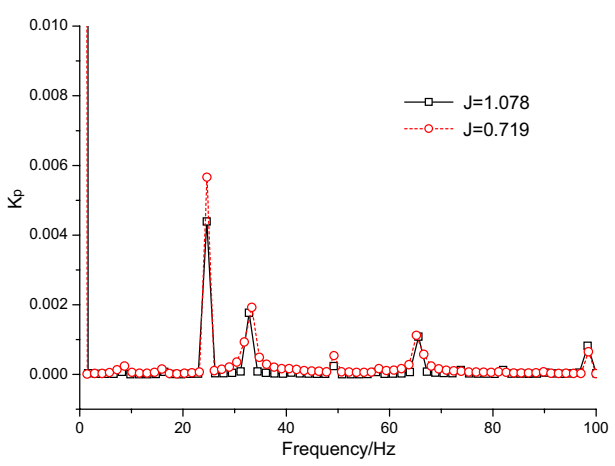

c Frequency-domain curve of fluctuating pressure coefficient of $\mathrm{P} 2$ under different advance coefficients

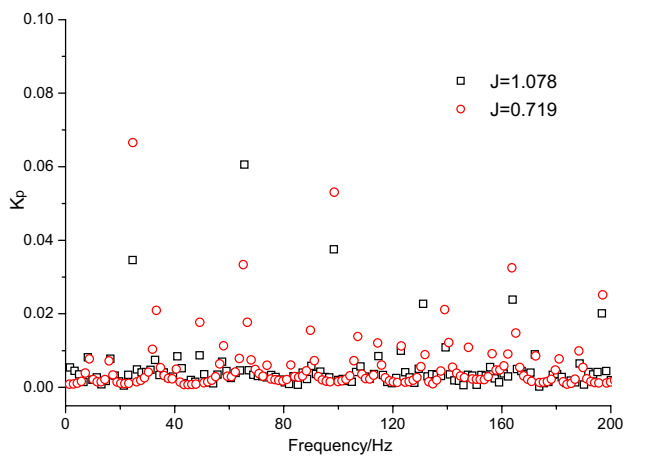

b Frequency-domain curve of fluctuating pressure coefficient of P01 under different advance coefficients

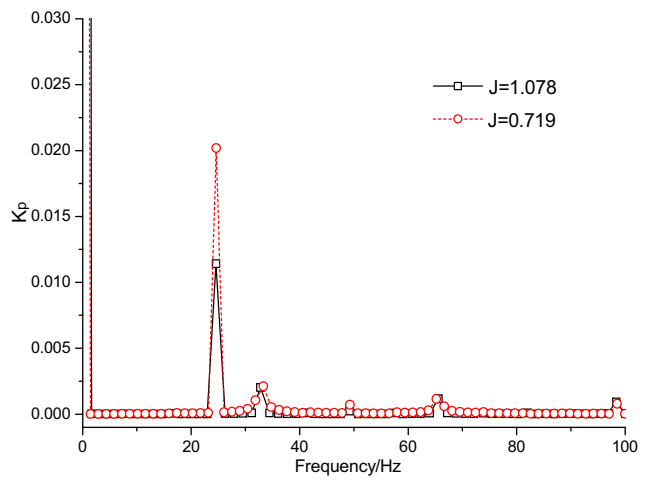

d Frequency-domain curve of fluctuating pressure coefficient of P4 under different advance coefficients

Fig. 16 Frequency-domain curve of fluctuating pressure induced by propeller under different advance coefficients $\left(\beta=7.5^{\circ}\right)$

\subsubsection{The calculation results of fluctuating pressure}

To analyze fluctuating pressure induced by propeller, the fluctuating pressure of $\mathrm{P} 0$ and $\mathrm{P} 01$ as representative only is analyzed and compared. In Fig. 20, it shows that along with oblique flow angle increasing, the pulsating amplitude of fluctuating pressure increases slightly,

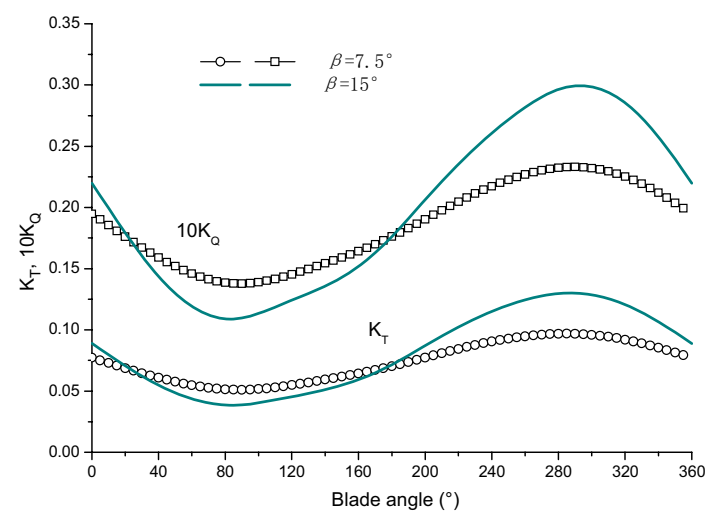

Fig. 17 Curve of thrust coefficient and torque coefficient of single blade under different oblique flow angles $(J=1.078)$ but its increase range is far less than unsteady bearing force's. It shows that the influence of oblique flow angle on unsteady bearing force is greater than fluctuating pressure's.

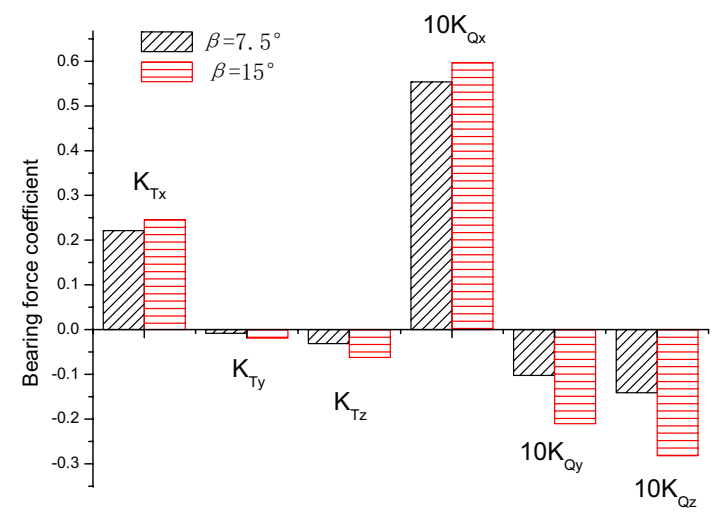

Fig. 18 Time-average value of unsteady bearing force coefficient under different oblique flow angles $(J=1.078)$ 


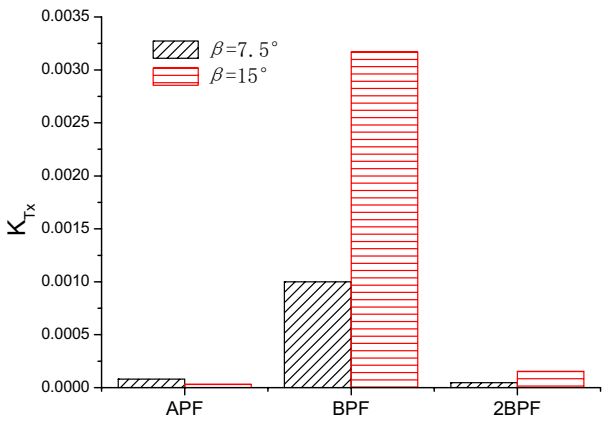

a Pulsating peaks of thrust coefficient

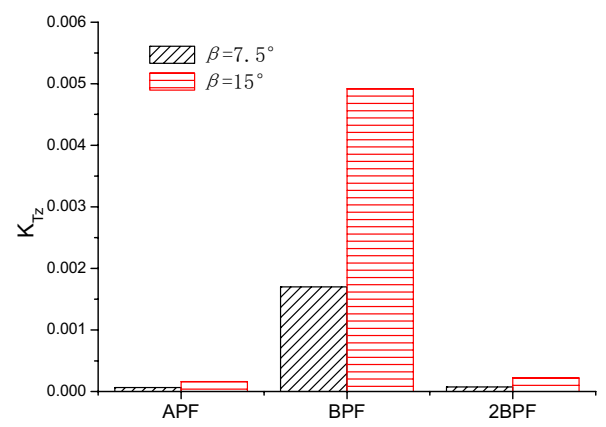

C Pulsating peak of transverse force coefficient

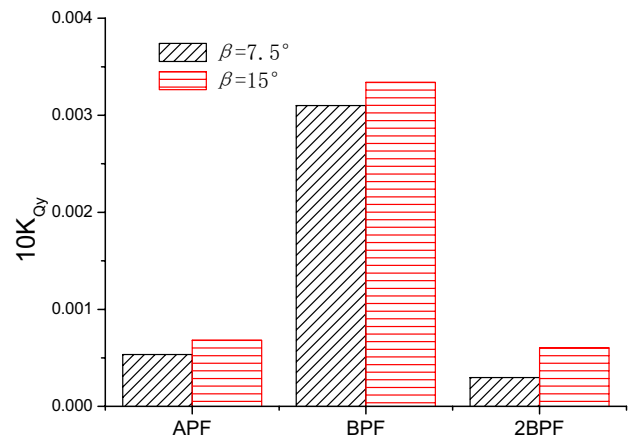

e Pulsating peak of vertical bending moment coefficient
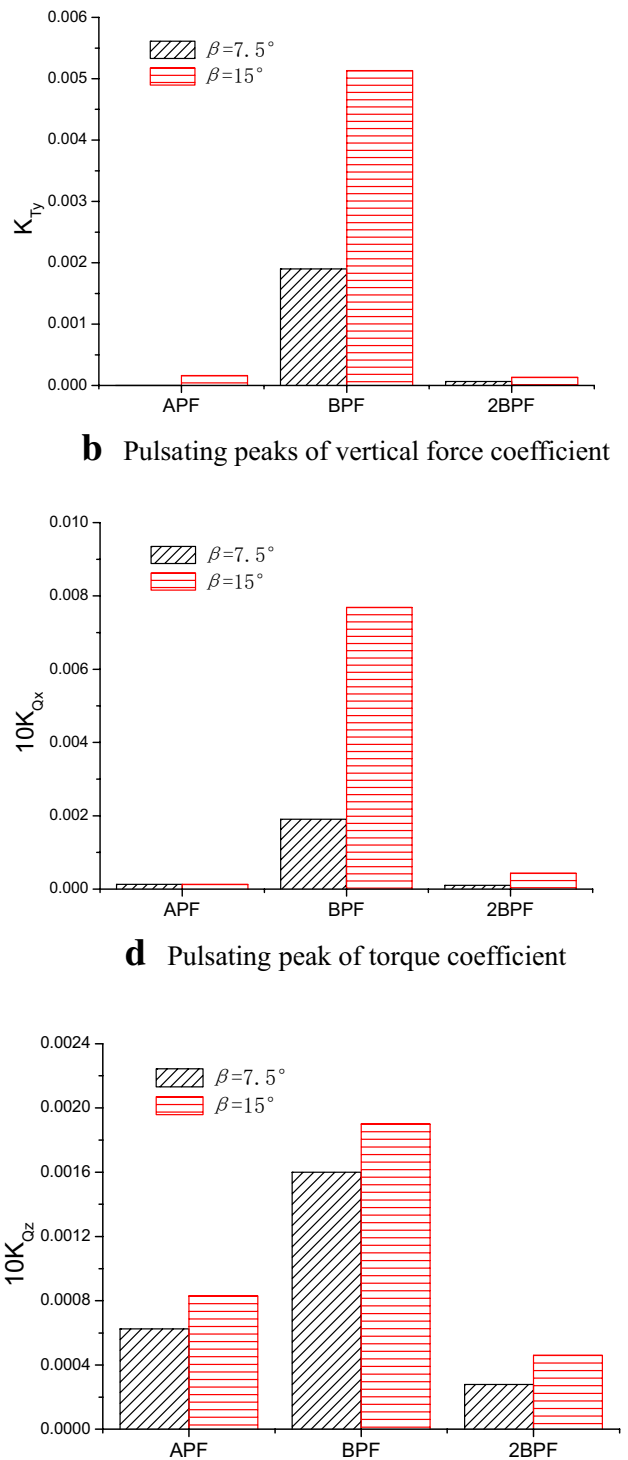

f Pulsating peak of transverse bending moment coefficient

Fig. 19 Pulsating peaks of unsteady bearing force coefficient under different oblique flow angles $(J=1.078)$

\section{Conclusions}

In this paper, sliding grid technique was applied, through adjusting magnitude and direction of flow, hydrodynamic performance of propeller and induced exciting force under different advance coefficients and oblique flow angles were done numerical calculation. Through comparing with test results and the literature value, accuracy of the calculation method is fully verified, and following conclusions are gotten:

1. Comparing axial flow, the thrust and torque of propeller working in oblique flow will increase. It indicates that the load of propeller working in oblique flow will aggravate.

2. In the process of blade rotating a round in oblique flow, due to the change of circumferential velocity, it results in continual change of attack angle of blade section. When $\theta=90^{\circ}$, the load of blade is smallest; when $\theta$ $=270^{\circ}$, the load of blade is largest.

3. Side force and bending moment comparing with thrust and torque are small amount in oblique flow, while transverse force and transverse bending moment is greater than vertical force and vertical bending moment. It indicates that transverse velocity compo- 


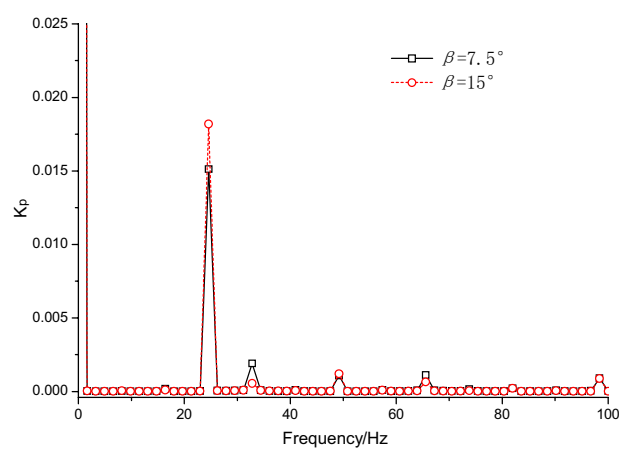

a Frequency-domain curve of fluctuating pressure coefficient of $\mathrm{P} 0$

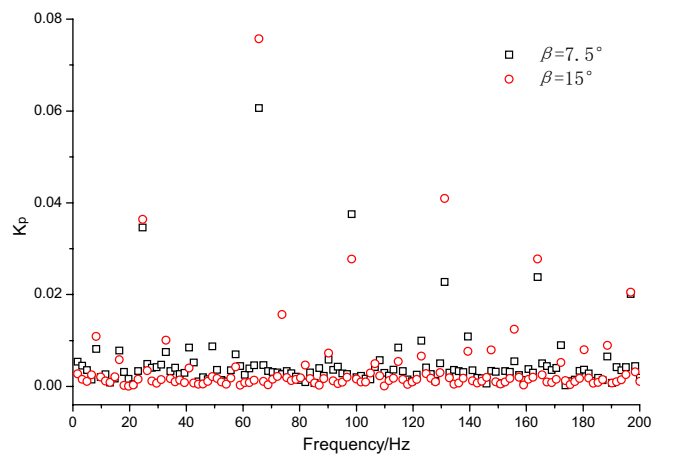

b Frequency-domain curve of fluctuating pressure coefficient of $\mathrm{P} 01$

Fig. 20 Frequency-domain curve of fluctuating pressure induced by propeller under different oblique flow angles $(J=1.078)$

nent will cause larger transverse force of propeller. It will have bad influence on ship maneuverability.

4. The influence of advance coefficient on fluctuating pressure in oblique flow is bigger than bearing force's. The smaller advance coefficient is the larger pulsating peak of fluctuating pressure induced by propeller.

5. Under different oblique flow angles, the time-average value and pulsating value of bearing force with the increase of oblique flow angle increase both obviously. But the change of pulsating peak of fluctuating pressure is not big. It shows that the influence of oblique flow angle on unsteady bearing force is larger than the influence on fluctuating pressure.

The working condition in this paper is propeller in oblique flow. The influence of free surface and wave has not been considered. Based on the study of this paper, next work will research characteristics of unsteady exciting force in waves.

Acknowledgements The research was financially supported by the National Natural Science Foundation of China (Grant NO.51309061) and the Scientific Research Foundation for the Heilongjiang Province Post-doctor (Grant NO. LBH-Q15024).

Open Access This article is distributed under the terms of the Creative Commons Attribution 4.0 International License (http:// creativecommons.org/licenses/by/4.0/), which permits unrestricted use, distribution, and reproduction in any medium, provided you give appropriate credit to the original author(s) and the source, provide a link to the Creative Commons license, and indicate if changes were made.

\section{References}

1. Merz S, Kinns R, Kessissoglou NJ (2005) Structure and acoustic responses of a submarine hull due to propeller force. J Sound Vib 325:266-286
2. Kornev N, Taranov A, Shchukin E, Kleinsorge L (2011) Development of hybrid URANS-LES methods for flow simulation in the ship stern area. J Ocean Eng 38:1831-1838

3. Wei Y, Wang Y (2013) Unsteady hydrodynamics of blade forces and acoustic responses of a model scaled submarine excited by propeller's thrust and side-forces. J Sound Vib 332:2038-2056

4. Jingming Y, Ying X, Youwen P (2013) Analysis of prediction method of forces exerted on propeller bearing. J Ship Eng 03:16-18

5. Yanshou T, Wei H (2006) Calculation of unsteady shaft forces of propeller (in Chinese). J Ship Ocean Eng 02:42-46

6. Ruxing C, Ruiping Z, Xichen L (2014) Numerical simulation of the propeller-induced force based on CFX (in Chinese). J Wuhan Univ Technol 07:73-79

7. Xuemei F, Chuanjing L, Qiong W, Rongquan C (2012) Numerical simulation of propeller cavitation in uniform flow (in Chinese). J Shipbuild China 03:18-27

8. Jian H (2006) Research on propeller cavitation characteristics and low noise propeller design. Ph.D. Thesis, Harbin Eng Univ

9. ITTC Propulsion Committee (1998) In: Proceedings of propeller RANS/Panel method workshop, Grenoble, France

10. Yao J (2015) Investigation on hydrodynamic performance of a marine propeller in oblique flow by RANS computations. Int $\mathbf{J}$ Nav Arch Ocean Eng 7:69

11. Wang C, Sun S, Li L, Ye L (2016) Numerical prediction analysis of propeller bearing force for full-scale hull-propeller-rudder system. Int J Nav Arch Ocean Eng 06(003):589-601

12. Jessup S (1982) Measurements of the pressure distribution on two model propellers. J Techn Rep, DTNSRDC82/0356.

13. Gaggero S, Villa D, Brizzolara S (2010) RANS and PANEL method for unsteady flow propeller analysis. In: Proceedings of the 9th international conference on hydrodynamics

14. Krasilnikov V, Zhang Z, Hong F (2009) Analysis of unsteady propeller blade forces by RANS. In: First international symposium on marine propulsors smp'09, Trondheim, Norway

15. Leishmann JG, Beddoes TS (1989) A semi-empirical model for dynamic stall. J Am Helicopter Soc 34(3):3-17

16. Zhenliang Q (1999) Investigation on the transverse force of propeller oblique flow effect upon the maneuver of river boat (in Chinese). J Nav China 02:38-42

17. Blake WK (1996) Mechanics of flow-induced sound and vibration. Orlando Academic Press Inc, Cambridge

18. Liang L, Chao W, Shengxia S, Shuai S (2015) Numerical prediction analysis of propeller exciting force for hull-propeller-rudder system (in Chinese). J Wuhan Univ Technol 39:768-772 